\title{
Effect of Some Biofertilizers and Humic Acid Application on Olive Seedlings Growth under Irrigation with Saline Water
}

\author{
Mona, M. El-Shazly ${ }^{1}$ and Wael M.Ghieth ${ }^{2}$
}

\begin{abstract}
The present study was conducted to examine the effect of humic acid concentration $(0,0.5,1$ and $1.5 \mathrm{ml} / \mathrm{L})$ and some of biofertilization treatments (control, Azotobacter chroococcum, Mycorrhizae (Glomus macrocarbium) and mix of Azotobacter chroococcum + Mycorrhizae on olive seedling which grown under three levels of saline water $(2000,3000$ and $4000 \mathrm{ppm})$. this experiment was carried out during two successive seasons (2015 and 2016) on Olive seedlings Picual cultivars grown in El-Sheikh Zuwayid station, Desert Research Center North Sinai governorate, Egypt. Based on growth parameters data showed that salinity level (2000ppm) produced the highest significant parameters of the olive seedling; for seedling height, trunk diameter, Branch number., Leaf number., leaf length, leaf width, leaf area, and also the fresh and dry weight of shoot and root system. The lowest values were recorded for salinity level $(4000 \mathrm{ppm}$ through the two seasons. Salinity level at $2000 \mathrm{ppm}$ gives the chance of growing plant to complete all of its physiological processes at a proper time than that of high concentration. Highest salinity concentration $4000 \mathrm{ppm}$ caused a decline in all the studied parameters throughout both studied seasons. Increasing humic acid levels from 0.5 to $1.5 \mathrm{ml} / \mathrm{L} \%$ increased significantly all studied parameters when compared with control (0) in the two studied seasons. Application of biofertilization treatments either singly or mixed enhanced growth and plant biomass of olive seedling under different salinity treatment. Mixed two types of biofertilzer had a significant effect on seedling growth than control and one type of biofertilizer treatments. In addition, Macronutrient content in olive seedling leaf positively affected with humic acid concentration and biofertilization treatments. Mixed biofertilization treatment resulted in higher values of soil microbiological properties, i.e. total microbial counts, Azotobacter densities, Mycorrhizal infection percentage, no. of mycorrhizal spores /gm, microbial enzymes in soil (Dehydrogenase, Nitrogenase and Phosphatase). It can be concluded that, to mitigate the negative impact of salinity of olive seedling we recommend to use humic acid $(1.5 \mathrm{ml} / \mathrm{L} \%)$ with the treatment of biofertilizer (Mycorrhiza and Azotobacter chroococcum).
\end{abstract}

Keywords: Olive seedling, Salinity, Humic acid, Biofertilzer, Azotobacter, Mycorrhizae.

DOI: 10.21608/ASEJAIQJSAE.2019.33657

${ }^{1}$ Soil Fertility and Microbiology Department, Desert Research Center

${ }^{2}$ Pomology unit, Department of plant production, Desert Research Center

Received April 14, 2019, Accepted May 21, 2019

\section{INTRODUCTION}

Olive (Olea europaea $L$ ) is considered as a moderately salt tolerant fruit crop, it is better than citrus, but less than Palm tree, irrigation with saline water can be harmful to many of olive tree with negative impacts on growth and behavior. In most coastal Mediterranean areas, in which olive is cultivated, the increased need for good quality water for human utilization limits the use of water for irrigation. Therefore, in those areas, large quantities of low-quality water are available especially saline water, which should be used to replenish irrigation requirements. Salinization of soils and waters is one of the world's most serious environmental problems in agriculture; it is limiting crop growth and productivity especially in arid and semi-arid regions (Sepaskhah and Yarami, 2010). Toxicity of $\mathrm{Na}^{+}$in metabolic processes results from its ability to compete with $\mathrm{K}^{+}$for binding sites and to inactivate enzymes and essential cellular functions and, consequently, crops growing in saline soils may suffer the dual injury of $\mathrm{Na}^{+}$ toxicity and low $\mathrm{K}^{+}$concentrations (Munns and Tester, 2008)

Humic acids (HA) are the most active components of soil and compost organic matter, stimulate plant growth and consequently yield by acting on mechanisms involved in cell respiration, photosynthesis, protein synthesis, water and nutrient uptake, enzyme activities (Chen et al.,2004). In particular, optimal concentrations able to affect and stimulate plant growth have been generally found in the range of $50-300 \mathrm{mg} / \mathrm{L}$, but positive effects have been also exerted by lower concentrations (Chen et al., 2004). A distinction on the effects of humic acids should be made between indirect and direct effects on plants growth. Indirect effects are mainly exerted through properties such as enrichment in soil nutrients, increase of microbial population, higher cation exchange capacity, improvement of soil structure; whereas direct effects are various biochemical actions exerted at the cell wall, membrane or cytoplasm and mainly of hormonal nature (Varanini and Penton, 2001; Chen et al., 2004). Magdi et al.,(2011) reported that bio-fertigation of microbial inocula and humic substances could be used as a complementary for 
mineral fertilizers to improve yield and quality of cowpea under sandy soil conditions which protect the environment chemical pollution and its harmful effect on human and animal health. A foliar application of HA increased the vegetative growth of olive cuttings (Hartwigsen and Evansmicheal, 2000; Muscolo and Sidari, 2007; Schmidt et al. 2007; Zandonadi et al. 2007).

Biofertilizers are biological products containing living microorganisms that, when applied to seed, plant surfaces, or soil, promote growth by several mechanisms such as increasing the supply of nutrients, increasing root biomass or root area, and increasing nutrient uptake capacity of the plant (Vessey 2003). Biofertilizers can be used as complements to mineral fertilizers (Canbolat et al. 2006). Microbial inoculants mainly include freeliving bacteria, fungi, and arbuscular mycorrhizal fungi (AMF) (Berg 2009; Dodd and Ruiz-Lozano 2012; Vessey 2003) that were isolated from a variety of environments including soil, plants, plant residues, water, and composted manures.

Arbuscular Mtycorrhizal Fungi (AMF) is known to enhance plant establishment and drought tolerance (Querejeta et al. 2003) by various mechanisms including (a) improved water uptake, by which AMF effectively extend plant roots making the uptake of water much more efficient; (b) better mineral nutrition, especially phosphorus, as a consequence of effectively extending roots; (c) alterations in root architecture;(d) modification of some physiological and enzymatic activities, especially those involved in plant antioxidative responses; and (e) induction of the plant hormone Abscisic acid (ABA), which can play an important role in mediating some plant responses to different stresses including drought (Gamalero et al. 2002). Under these conditions, AMF enhanced root surface area and promoted dense root growth, resulting in improved drought tolerance. Moreover, plants colonized by AMF were able to maintain higher water use efficiency, and growth was increased at a faster rate when irrigation was restored. Such adjustment of osmotic potential is one of the most important factors for plant survival under drought conditions. In addition, AMF may affect plant water potential by modification of soil structure.

Hyphae of AMF can improve soil structure by binding soil particles and producing glomalin, an insoluble gluelike substance (Augé 2001). AMF may also play a role in the protection of roots from heavy metal toxicity by mediating interactions between metals and plant roots (Leyval et al. 1997).

The beneficial effect of symbiotic nitrogen fixer Azotobacter chroococcum as free-living $\mathrm{N}_{2^{-}}$fixing is attributed to fix atmospheric nitrogen, synthesis of phytohormones and vitamins, inhibiting plant ethylene synthesis, enhancing stress resistance and improving nutrient uptake (Massoud et al., 2013).

Co-inoculation of AMF and Plant growth regulating rhizobacteria (PGPR) is also a promising strategy to increase plant tolerance to salinity and drought. It was reported that co-inoculation of the AMF Glomus mosseae and G. intraradices and PGPR Bacillus spp. on lettuce increased plant growth, photosynthetic rate, water use efficiency, and stomatal conductance after drought stress. The effect of the co-inoculation was better than inoculation with only AMF or Bacillus spp. Furthermore, Bacillus spp. inoculation also improved AMF colonization and growth (Vivas et al. 2003). The objectives of this study were to evaluate the effect of the application of humic acid and biofertilization on olive seedlings under three levels of saline water $(2000,3000$ and $4000 \mathrm{ppm}$ ).

\section{MATERIALS AND METHODS}

A field experiment was conducted at El-Sheikh Zuwayid research station, Desert Research Center (DRC), North Sinai Governorate for two growing seasons (2015 and 2016) on olive seedlings to study the effect of Biofertilization treatments and humic acid concentrations on the growth of olive seedling under three different salinity levels. The experiment was laid out in a split split plot design with three replications.

Three salinity levels were used $(2000,3000$ and 4000 ppm) which obtained from El-Sheikh Zuwayid research station wells, four concentration of organic humic acid $(0,0.5,1$ and $1.5 \mathrm{ml}$ in 1 Liter of water) were applied as foliar spray with four biofertilization treatments (control, Azotobacter chroococcum, Mycorrhizae (Glomus Macrocarbium) and mix of Mycorrhiza and Azotobacter chroococcum). The seedling was about 1-year-old (Picual cultivar) planted at $6 \times 6 \mathrm{~m}$ apart grown in sandy soil, under drip irrigation system and nearly uniform in shape and received the common horticultural practices.

The chemical and physical characteristics of the experimental soil are presented in Table. 1. The rate of fertilizers added were $10 \mathrm{~m}^{3}$ chicken manure per feddan, 500 grams of superphosphate, 250 grams ammonium sulfate and 250 grams potassium sulfate per tree were applied at the time of the winter service followed by adding $500 \mathrm{ml}\left(5 \times 10^{6} \mathrm{cfu}\right)$ of pure active culture of Azotobacter chroococcum and $100 \mathrm{~g}$ of crude inoculum of Glomus macrocarpum $(\approx 10$ spores/g) singly and mixed to the root zone of olive trees. 
Table 1. The main physical and chemical characteristics of the experimental soil of El-sheikh Zuwayid research station.

\begin{tabular}{|c|c|c|c|c|c|c|c|c|c|c|c|c|}
\hline \multirow[t]{2}{*}{$\begin{array}{c}\text { Physical } \\
\text { parameters }\end{array}$} & \multicolumn{2}{|c|}{$\begin{array}{l}\text { Very coarse } \\
\text { sand \% }\end{array}$} & \multicolumn{2}{|c|}{$\begin{array}{c}\text { Coarse sand } \\
\%\end{array}$} & $\begin{array}{c}\text { Medium } \\
\text { sand \% }\end{array}$ & \multicolumn{2}{|r|}{$\begin{array}{c}\text { Fine } \\
\text { sand \% }\end{array}$} & $\begin{array}{c}\text { Very fine } \\
\text { sand }\end{array}$ & \multicolumn{2}{|c|}{ Silt and clay \% } & \multicolumn{2}{|c|}{ Soil texture } \\
\hline & \multicolumn{2}{|c|}{0.31} & \multicolumn{2}{|c|}{1.91} & 40.05 & & 53.52 & 2.44 & & .75 & Sanc & y soil \\
\hline \multirow{3}{*}{$\begin{array}{c}\text { Chemical } \\
\text { parameters }\end{array}$} & pH & E.C. & O.C.\% & T.N. & \multicolumn{4}{|c|}{ Water soluble cations meq/l } & \multicolumn{4}{|c|}{ Anions meq/I } \\
\hline & & $\mathrm{dS} / \mathrm{m}$ & & $\%$ & $\mathrm{Ca}^{++}$ & $\mathbf{M g}^{++}$ & $\mathrm{Na}^{+}$ & $\mathbf{K}^{+}$ & $\mathrm{CO}_{3}^{--}$ & $\mathrm{HCO3}^{--}$ & $\mathrm{Cl}^{-}$ & $\mathrm{SO}_{4}^{--}$ \\
\hline & 7.69 & 1.71 & 0.053 & 0.0016 & 7.94 & 2.78 & 1.62 & 3.81 & 4.86 & - & 5.62 & 5.69 \\
\hline
\end{tabular}

These microbial and humic acid spray treatments were applied at three growth stages before spring growth cycle (March), after 2 months from the first treatment (May) and after 2 months from the second treatment (July) in the two studied seasons.

\section{Preparation of microbial inoculate}

The heavy cell suspension of Azotobacter chrocchocum was obtained by growing A.chroococcum on Ashby's media for 7 days at $28 \pm 22^{\circ} \mathrm{C}$. The proliferation of mycorrhizal spores was carried out by pot culture; mycorhizael spores were obtained by wetsieving method (Gerdemann and Nicolson, 1963). The isolated spores were proliferated with the barley (Hordeum vulgare) as a host plant in the pots for production of mycorrhizal inoculum. Then the rhizosphere soil till depth $15 \mathrm{~cm}$ from the roots and roots were used as a mycorrhiza crude inocula after 10 days from cutting the vegetative parts.

\section{Sampling and determinations}

\section{Growth and seedling weight parameters}

In late October, tree height $(\mathrm{cm})$ was measured for each season also trunk diameter, Branch number, leaves number, Leaves length, leaf width and leaf area were determined for two seasons according to Ghieth, (2009). Fresh and dry weight for a seedling shoot and root system were determined at the second season.

\section{Determination of Macronutrients (NPK)}

Leaves samples were collected at the end of June 2016 and then dried at $70^{\circ} \mathrm{C}$ in a hot air oven for $3 \mathrm{hrs}$. The dried samples were ground and then digested for nitrogen, phosphorus, potassium analyses. Nitrogen, Phosphorus and Potassium were measured according to Page et al. (1982).

\section{Microbiological analysis}

Rhizosphere soil samples were collected to determine the microbiological parameters, the root hairs collected for detection the percentage of mycorrhizal colonization.
Total microbial counts were determined according to Nautiyal (1999), Azotobacter densities were determined by using the most probable number (MPN) method after incubating the tubes at $28+2{ }^{\circ} \mathrm{C}$ for 10 days on modified Ashby's medium (Becking , 2006). Total actinomycetes count was determined on starch nitrate medium (Waksman \& lechevalier, 1962).

The mycorrhizal colonization in roots was estimated by the gridlines intersect method of Giovannetti \& Mossa, (1980).

\section{Statistical analysis}

Data were subjected to statistical analysis using the method described by Snedecor and Cochran (1990). The least significant difference (L.S.D.) was used to differentiate means according to (Waller and Duncan, 1969).

\section{RESULTS AND DISCUSSION}

\section{Plant growth characteristics}

Data in Table 2 indicates that in the two growing seasons, seedling height, trunk diameter and branches number measurements exhibited significant differences for different salinity levels. The highest increases were obtained with salinity level (2000 ppm) being 83.59 $\mathrm{cm}, 0.97 \mathrm{~cm}$ and 16.89 respectively, while $4000 \mathrm{ppm}$ gave the lowest values being $64.69 \mathrm{~cm}, 0.85 \mathrm{~cm}$ and 11.99 for height, trunk diameter and branches number in the first season while the same parameters gave 123.4 $\mathrm{cm}, 1.24 \mathrm{~cm}$ and 13.01 with salinity level (2000 ppm) while it gave $101.36 \mathrm{~cm}, 1.1 \mathrm{~cm}$ and 11.43 respectively with salinity level (4000 ppm) in the second season. Salinity stress reduces height by nearly $21.7 \%$ for 4000 ppm compared with 2000 ppm at second season; this may be due to the negative impact of salinity on plant growth. Salinity stress depresses plant growth and development at different physiological levels. The mechanism by which salt stress damage plants are still a discussing matter due to the very complex nature of the salt stress in plants (Zhu, 2001). 
Table 2. Effect of water irrigation Salinity, humic acid concentration and biofertilization treatments on height, trunk diameter and branch no. of olive seedling in the two growing seasons.

\begin{tabular}{|c|c|c|c|c|c|c|}
\hline \multirow[t]{2}{*}{ Treatment } & \multicolumn{3}{|c|}{$1^{\text {st }}$ season } & \multicolumn{3}{|c|}{$2^{\text {nd }}$ season } \\
\hline & $\begin{array}{l}\text { Height } \\
\text { (cm) }\end{array}$ & $\begin{array}{l}\text { Trunk Diameter } \\
\text { (cm) }\end{array}$ & $\begin{array}{c}\text { Branch } \\
\text { No. }\end{array}$ & $\begin{array}{l}\text { Height } \\
\text { (cm) }\end{array}$ & $\begin{array}{l}\text { Trunk Diameter } \\
\text { (cm) }\end{array}$ & $\begin{array}{c}\text { Branch } \\
\text { No. }\end{array}$ \\
\hline \multicolumn{7}{|c|}{ Salinity(ppm) } \\
\hline 2000 & 83.59 & 0.97 & 16.89 & 123.34 & 1.24 & 13.01 \\
\hline 3000 & 72.24 & 0.86 & 13.80 & 112.70 & 1.16 & 12.13 \\
\hline 4000 & 64.96 & 0.85 & 11.99 & 101.36 & 1.10 & 11.43 \\
\hline L.S.D at $5 \%$ & 0.24 & 0.73 & 0.30 & 0.36 & 0.02 & 0.26 \\
\hline \multicolumn{7}{|c|}{ Humic acid (ml/L) } \\
\hline 0 & 56.56 & 0.84 & 11.67 & 96.71 & 1.08 & 10.03 \\
\hline 0.5 & 70.00 & 0.85 & 13.65 & 108.36 & 1.11 & 11.24 \\
\hline 1.0 & 77.70 & 0.89 & 14.66 & 115.36 & 1.18 & 12.76 \\
\hline 1.5 & 90.72 & 0.91 & 16.92 & 129.36 & 1.30 & 14.74 \\
\hline L.S.D at $5 \%$ & 0.36 & 0.01 & 0.33 & 0.23 & 0.03 & 0.38 \\
\hline \multicolumn{7}{|c|}{ Biofertilization treatments } \\
\hline Control & 37.80 & 0.84 & 11.08 & 66.50 & 1.01 & 10.31 \\
\hline A.chrococcum & 74.62 & 0.86 & 13.07 & 117.88 & 1.13 & 12.17 \\
\hline G.macrocarbium & 83.44 & 0.90 & 15.40 & 125.72 & 1.23 & 11.94 \\
\hline Mixture & 99.26 & 0.92 & 17.23 & 139.96 & 1.30 & 14.35 \\
\hline L.S.D at $5 \%$ & 0.41 & 0.15 & 0.66 & 0.37 & 0.03 & 0.21 \\
\hline
\end{tabular}

Among different rates of humic acid, there were significant variations at the level $(p>0.05)$. This may be due to humic acid is known to promote nutrient uptake as a chelating agent and improves vegetative characteristics, nutritional status and leaf pigments (Eissa et al, 2007).

The highest concentration of humic acid recorded the highest increment for height, trunk diameter and branches number of Olive seedling being $60.39,8.33$ and $44.98 \%$ of increase than control at first season and $33.76,20.37$ and $46.95 \%$ of increase than control at second season respectively. The results are in agreement with Zandonadi et al. 2007 they reported that a foliar application of humic acid increased the vegetative growth of olive cuttings. In particular, optimal concentrations able to affect and stimulate plant growth have been generally found in the range of $50-300 \mathrm{mg} \mathrm{L}^{-}$ 1 , but positive effects have been also exerted by lower concentrations (Chen et al., 2004).

Biofertilization treatments showed a stimulating effect on different growth parameters either alone or in combination. Mixed treatments exerted percentage increase height, trunk diameter and branches number by $162,9.52$ and $55.50 \%$ at a $1^{\text {st }}$ season, and by 110.64 , 28.71 and $39.18 \%$ at a $2^{\text {nd }}$ season, respectively. For single treatments, mycorrhizae give the highest value compared to Azotobacter. Such increases by the different biofertilization treatments emphasize the fact that biofertilization stimulates vegetative growth through different mechanisms like improve plant metabolic activity, enhance nutrient uptake, secretion of plant growth promoting substances like hormones, vitamins, nitrogen fixation, organic acid production (Muhammed et al., 2012).

Table 3, clearly showed that humic acid (HA) treatments at a concentration $(1.5 \mathrm{ml} / \mathrm{L})$ with Mixed Biofertilization treatments and first salinity level significantly ( $p>0.05$ ) increased all the studied parameters; i.e., seedling height, trunk diameter and branch no. than untreated control during $1^{\text {st }}$ and $2^{\text {nd }}$ season. The positive influence of HA on plant growth and productivity, which seems to be concentration specific, could be mainly due to the hormone-like activity of HA through its involvement in cell respiration, photosynthesis, oxidative phosphorylation, protein synthesis, and various enzymatic reactions (Muscolo and Sidari 2007). The highest values of plant height, trunk diameter and branches number (134.40, 1.06 and 18.66 at $1^{\text {st }}$ season) and (177.80, 1.76 and $24.74)$ at $2^{\text {nd }}$ season) respectively, were recorded at the concentration of $1.5 \mathrm{HA}$. These results may be due to the role of HA in enhancing some physiological and biochemical aspects (Schmidt et al. 2007). 
Table 3. Interaction effect of water irrigation Salinity, humic acid and biofertilization treatments on some of the tree parameters of olive seedling in the two growing seasons.

\begin{tabular}{|c|c|c|c|c|c|c|c|c|}
\hline \multirow{2}{*}{$\begin{array}{l}\text { Salinity } \\
\text { ppm }\end{array}$} & \multirow{2}{*}{$\begin{array}{l}\text { Humic } \\
\mathrm{ml} / \mathrm{L}\end{array}$} & \multirow{2}{*}{$\begin{array}{l}\text { Biofertilization } \\
\text { treatments }\end{array}$} & \multicolumn{3}{|c|}{$1^{\text {st }}$ season } & \multicolumn{3}{|c|}{$2^{\text {nd }}$ season } \\
\hline & & & $\begin{array}{c}\text { Height } \\
\text { (cm) }\end{array}$ & $\begin{array}{c}\text { Trunk } \\
\text { Diameter }(\mathrm{cm})\end{array}$ & $\begin{array}{c}\text { Branch. } \\
\text { No }\end{array}$ & $\begin{array}{c}\text { Height } \\
\text { (cm) }\end{array}$ & $\begin{array}{c}\text { Trunk } \\
\text { Diameter }(\mathrm{cm})\end{array}$ & $\begin{array}{l}\text { Branch } \\
\text { No. }\end{array}$ \\
\hline \multirow[t]{16}{*}{2000} & \multirow[t]{4}{*}{0} & Control & 32.66 & 0.81 & 9.38 & 61.14 & 0.95 & 10.74 \\
\hline & & A.chrococcum & 65.80 & 0.84 & 9.80 & 108.26 & 1.12 & 12.46 \\
\hline & & G.macrocarbium & 70.00 & 0.87 & 10.74 & 112.94 & 1.23 & 15.86 \\
\hline & & Mixture & 71.40 & 0.99 & 12.18 & 111.54 & 1.25 & 16.34 \\
\hline & \multirow[t]{4}{*}{0.5} & Control & 40.60 & 0.83 & 10.26 & 62.54 & 0.94 & 12.14 \\
\hline & & A.chrococcum & 81.20 & 0.84 & 11.66 & 126.46 & 1.13 & 14.94 \\
\hline & & G.macrocarbium & 91.98 & 0.94 & 12.18 & 134.86 & 1.26 & 17.74 \\
\hline & & Mixture & 105.98 & 1.02 & 13.58 & 149.80 & 1.27 & 17.74 \\
\hline & \multirow[t]{4}{*}{1} & Control & 46.20 & 0.88 & 11.66 & 65.38 & 1.05 & 13.06 \\
\hline & & A.chrococcum & 89.60 & 0.88 & 13.06 & 138.18 & 1.25 & 17.26 \\
\hline & & G.macrocarbium & 99.86 & 0.95 & 13.58 & 142.80 & 1.39 & 20.06 \\
\hline & & Mixture & 123.66 & 1.05 & 15.86 & 169.40 & 1.30 & 19.14 \\
\hline & \multirow[t]{4}{*}{1.5} & Control & 50.40 & 0.90 & 13.58 & 78.40 & 1.16 & 13.11 \\
\hline & & A.chrococcum & 107.80 & 0.95 & 15.86 & 149.80 & 1.30 & 19.60 \\
\hline & & G.macrocarbium & 99.86 & 0.99 & 16.38 & 116.66 & 1.44 & 24.26 \\
\hline & & Mixture & 134.40 & 1.06 & 18.66 & 177.80 & 1.76 & 24.74 \\
\hline \multirow[t]{16}{*}{3000} & \multirow[t]{4}{*}{0} & Control & 29.40 & 0.80 & 8.40 & 62.06 & 0.88 & 9.34 \\
\hline & & A.chrococcum & 58.80 & 0.81 & 10.26 & 99.86 & 1.05 & 10.26 \\
\hline & & G.macrocarbium & 67.20 & 0.83 & 9.80 & 109.20 & 1.15 & 13.06 \\
\hline & & Mixture & 64.86 & 0.85 & 11.66 & 110.18 & 1.23 & 13.54 \\
\hline & \multirow[t]{4}{*}{0.5} & Control & 35.00 & 0.81 & 9.80 & 63.98 & 0.92 & 10.26 \\
\hline & & A.chrococcum & 67.20 & 0.83 & 11.20 & 109.20 & 1.11 & 11.66 \\
\hline & & G.macrocarbium & 77.00 & 0.87 & 10.78 & 132.06 & 1.23 & 13.54 \\
\hline & & Mixture & 98.00 & 0.88 & 13.06 & 148.86 & 1.25 & 16.80 \\
\hline & \multirow[t]{4}{*}{1} & Control & 39.66 & 0.85 & 10.78 & 67.66 & 0.97 & 11.20 \\
\hline & & A.chrococcum & 77.00 & 0.84 & 12.60 & 119.46 & 1.12 & 13.06 \\
\hline & & G.macrocarbium & 82.60 & 0.90 & 12.18 & 124.60 & 1.26 & 14.46 \\
\hline & & Mixture & 106.40 & 0.92 & 15.40 & 147.46 & 1.26 & 20.54 \\
\hline & \multirow[t]{4}{*}{1.5} & Control & 44.80 & 0.87 & 11.66 & 74.66 & 1.01 & 11.66 \\
\hline & & A.chrococcum & 95.20 & 0.92 & 14.46 & 137.66 & 1.15 & 14.46 \\
\hline & & G.macrocarbium & 96.60 & 0.94 & 14.00 & 138.18 & 1.27 & 16.34 \\
\hline & & Mixture & 124.18 & 0.95 & 18.20 & 171.26 & 1.64 & 22.40 \\
\hline \multirow[t]{16}{*}{4000} & \multirow[t]{4}{*}{0} & Control & 28.46 & 0.78 & 7.94 & 56.46 & 0.87 & 7.94 \\
\hline & & A.chrococcum & 56.98 & 0.78 & 9.80 & 97.06 & 0.99 & 9.80 \\
\hline & & G.macrocarbium & 64.40 & 0.81 & 8.86 & 106.40 & 1.08 & 10.74 \\
\hline & & Mixture & 66.78 & 0.84 & 9.34 & 107.34 & 1.11 & 11.20 \\
\hline & \multirow[t]{4}{*}{0.5} & Control & 30.80 & 0.80 & 8.86 & 58.34 & 0.91 & 9.80 \\
\hline & & A.chrococcum & 61.60 & 0.80 & 10.74 & 105.00 & 1.06 & 11.20 \\
\hline & & G.macrocarbium & 69.06 & 0.83 & 9.80 & 111.06 & 1.11 & 11.66 \\
\hline & & Mixture & 81.66 & 0.87 & 12.60 & 111.06 & 1.13 & 13.54 \\
\hline & \multirow[t]{4}{*}{1} & Control & 33.60 & 0.83 & 10.26 & 59.26 & 0.95 & 10.26 \\
\hline & & A.chrococcum & 64.40 & 0.81 & 12.14 & 110.14 & 1.11 & 12.60 \\
\hline & & G.macrocarbium & 72.24 & 0.85 & 11.66 & 113.86 & 1.12 & 13.06 \\
\hline & & Mixture & 98.00 & 0.90 & 14.00 & 124.60 & 1.27 & 14.00 \\
\hline & 1.5 & Control & 39.20 & 0.83 & 10.74 & 70.46 & 0.99 & 10.74 \\
\hline & & A.chrococcum & 69.02 & 0.90 & 13.54 & 112.46 & 1.11 & 13.54 \\
\hline & & G.macrocarbium & 85.40 & 0.91 & 13.54 & 127.40 & 1.23 & 15.86 \\
\hline & & Mixture & 117.60 & 0.94 & 15.40 & 149.34 & 1.50 & 16.34 \\
\hline L.S.D at & & & 0.97 & 0.069 & 1.36 & 0.10 & 0.71 & 1.21 \\
\hline
\end{tabular}


In addition, PGPR (plant growth promoting rhizobacteria) can improve plant growth, plant nutrition, root growth pattern, plant competitiveness and responses to external stress factors. PGPR have also been shown to induce systematic resistance (ISR) to fungal, bacterial, and viral pathogens in various crops such as bean, tomato, radish, and tobacco (Glick,1995).

Table 4 clearly showed that leaf measurements (leaf number, leaf length, leaf width and leaf area) negatively affected by increasing salinity during the two seasons. Different humic acid concentration positively affected leaf measurements while the highest concentration recorded the highest value for all measurements. While biofertilization treatments significantly affected leaf measurements especially, mixed biofertilization treatments (mycorrhizae+Azotobacter) recorded highest values being $167.31,6.18 \mathrm{~cm}, 1.37 \mathrm{~cm}$ and $6.37 \mathrm{~cm}^{2}$ for leaf number, leaf length, leaf width and leaf area respectively at first season compared to single treatments and control while, it recorded 381.12, 6.22 $\mathrm{cm}, 1.39 \mathrm{~cm}$ and $6.33 \mathrm{~cm}^{2}$ at second season respectively.

As for interaction effect data in Table 5 demonstrated that biofertilization treatments improved leaf measurements (leaf number, leaf length, leaf width and leaf area) under different salinity level and different humic acid concentration. The treatment of a mixture with the lower level of salinity and humic acid (1.5 $\mathrm{ml} / \mathrm{L}$ ) achieved the highest significant leaf measurements $\left(274.70,6.4 \mathrm{~cm}, 1.5 \mathrm{~cm}\right.$ and $\left.6.9 \mathrm{~cm}^{2}\right)$ in the first and (757.5, $6.77 \mathrm{~cm}, 1.53 \mathrm{~cm} 7.1 \mathrm{~cm}^{2}$ ) in the second season, respectively. Represented results clearly revealed that biofertilization treatments with humic acid concentration reduce the negative effect of salinity.

The obtained results in agreement with Muscolo and Sidari 2007 they reported the positive influence of HA on plant growth and productivity, which seems to be concentration specific, could be mainly due to the hormone-like activity of HA through its involvement in cell respiration, photosynthesis, oxidative phosphorylation, protein synthesis, and various enzymatic reactions. Also, Rojas et al., 2012 showed that Inoculation with Azotobacter strains has been shown to have generally positive effects under saline stress by facilitating uptake of $\mathrm{K}^{+}$and exclusion of $\mathrm{Na}^{+}$ as well as increasing phosphorous and nitrogen availability.

Tables 6 and 7 showed that, the highest olive fresh and dry weight was attained by salinity level 2000 so, increasing salinity level decease fresh and dry weights of Olive seedling in addition, fresh and dry weight of seedling was also affected by different humic acid concentration increasing humic acid concentration lead to increasing both fresh and dry weight for both shoot and root system in the second season.

Table 4. Specific effect of water irrigation Salinity, humic acid concentration and biofertilization treatments on Leaf measurements of olive seedling in the two growing seasons.

\begin{tabular}{|c|c|c|c|c|c|c|c|c|}
\hline \multirow[t]{2}{*}{ Treatment levels } & \multicolumn{4}{|c|}{$1^{\text {st }}$ season } & \multicolumn{4}{|c|}{$2^{\text {nd }}$ season } \\
\hline & $\begin{array}{l}\text { Leaf } \\
\text { No. }\end{array}$ & $\begin{array}{c}\text { Leaf } \\
\text { length }\end{array}$ & $\begin{array}{c}\text { Leaf } \\
\text { width }\end{array}$ & $\begin{array}{l}\text { Leaf } \\
\text { area }\end{array}$ & $\begin{array}{l}\text { Leaf } \\
\text { No. }\end{array}$ & $\begin{array}{c}\text { Leaf } \\
\text { length }\end{array}$ & $\begin{array}{c}\text { Leaf } \\
\text { width }\end{array}$ & $\begin{array}{l}\text { Leaf } \\
\text { area }\end{array}$ \\
\hline \multicolumn{9}{|c|}{ Salinity(ppm) } \\
\hline 2000 & 128.1 & 6.08 & 1.3 & 6.3 & 294.00 & 6.13 & 1.38 & 6.33 \\
\hline 3000 & 106.5 & 5.97 & 1.26 & 6.2 & 245.20 & 6.01 & 1.3 & 6.16 \\
\hline 4000 & 84.2 & 5.79 & 1.25 & 5.92 & 183.20 & 5.8 & 1.27 & 5.89 \\
\hline L.S.D at $5 \%$ & 0.985 & 0.0104 & 0.0227 & 0.0163 & 1.02 & 0.0196 & 0.0169 & 0.0255 \\
\hline \multicolumn{9}{|c|}{ Humic $(\mathrm{ml} / \mathrm{L})$} \\
\hline 0 & 84.61 & 5.65 & 1.22 & 5.72 & 183.62 & 5.71 & 1.296 & 5.72 \\
\hline 0.5 & 100.25 & 5.95 & 1.234 & 6.1 & 226.40 & 5.95 & 1.3 & 6.03 \\
\hline 1.0 & 113.22 & 6.03 & 1.28 & 6.25 & 257.60 & 6.03 & 1.32 & 6.27 \\
\hline 1.5 & 126.97 & 6.2 & 1.32 & 6.5 & 295.60 & 6.23 & 1.34 & 5.5 \\
\hline L.S.D at $5 \%$ & 0.995 & 0.0177 & 0.0204 & 0.0243 & 1.09 & 0.0232 & 0.0131 & 0.0164 \\
\hline \multicolumn{9}{|c|}{ Biofertilization treatments } \\
\hline Control & 75.8 & 5.51 & 1.2 & 5.7 & 154.88 & 5.59 & 1.27 & 5.85 \\
\hline A.chrococcum & 83.92 & 6.02 & 1.25 & 6.14 & 189.00 & 6.04 & 1.28 & 6.14 \\
\hline G.macrocarbium & 98.1 & 6.08 & 1.25 & 6.34 & 238.12 & 6.11 & 1.31 & 6.2 \\
\hline Mixture & 167.31 & 6.18 & 1.37 & 6.37 & 381.12 & 6.22 & 1.39 & 6.33 \\
\hline L.S.D at $5 \%$ & 1.13 & 0.0161 & 0.0124 & 0.0202 & 0.52 & 0.0176 & 0.0177 & 0.0168 \\
\hline
\end{tabular}


Table 5. Interaction effect of water irrigation Salinity, humic acid and biofertilization treatments on Leaf measurements of olive seedling in the two growing seasons.

\begin{tabular}{|c|c|c|c|c|c|c|c|c|c|c|}
\hline \multirow{2}{*}{$\begin{array}{l}\text { Salinity } \\
\text { ppm }\end{array}$} & \multirow{2}{*}{$\begin{array}{l}\text { Humic } \\
\mathrm{ml} / \mathrm{L}\end{array}$} & \multirow{2}{*}{$\begin{array}{l}\text { Biofertilization } \\
\text { treatments }\end{array}$} & \multicolumn{4}{|c|}{ 1 $^{\text {st }}$ season } & \multicolumn{4}{|c|}{$2^{\text {nd }}$ season } \\
\hline & & & $\begin{array}{l}\text { Leaf } \\
\text { No. }\end{array}$ & $\begin{array}{l}\text { Leaf } \\
\text { len. }\end{array}$ & $\begin{array}{l}\text { Leaf } \\
\text { wid. }\end{array}$ & $\begin{array}{l}\text { Leaf } \\
\text { area }\end{array}$ & $\begin{array}{c}\text { Leaf } \\
\text { No. }\end{array}$ & $\begin{array}{l}\text { Leaf } \\
\text { len. }\end{array}$ & $\begin{array}{l}\text { Leaf } \\
\text { wid. }\end{array}$ & $\begin{array}{l}\text { Leaf } \\
\text { area }\end{array}$ \\
\hline \multirow[t]{16}{*}{2000} & \multirow[t]{4}{*}{0} & Control & 72.00 & 5.3 & 1.2 & 5.6 & 188.3 & 5.3 & 1.31 & 5.66 \\
\hline & & A.chrococcum & 78.00 & 6 & 1.2 & 5.9 & 209.3 & 5.8 & 1.37 & 5.7 \\
\hline & & G.macrocarbium & 105.00 & 6 & 1.2 & 5.9 & 332.5 & 6.1 & 1.34 & 5.97 \\
\hline & & Mixture & 133.70 & 6.1 & 1.4 & 6 & 390.8 & 6.07 & 1.37 & 5.93 \\
\hline & \multirow[t]{4}{*}{0.5} & Control & 78.00 & 6 & 1.2 & 5.7 & 188.3 & 5.7 & 1.31 & 5.99 \\
\hline & & A.chrococcum & 81.70 & 6.1 & 1.2 & 6.4 & 236.8 & 6.13 & 1.33 & 6.2 \\
\hline & & G.macrocarbium & 117.00 & 6.1 & 1.3 & 6.4 & 365.0 & 6.17 & 1.35 & 6.25 \\
\hline & & Mixture & 204.70 & 6.2 & 1.4 & 6.3 & 550.8 & 6.13 & 1.47 & 6.37 \\
\hline & \multirow[t]{4}{*}{1} & Control & 83.30 & 6.1 & 1.3 & 5.8 & 210.0 & 5.74 & 1.36 & 6.09 \\
\hline & & A.chrococcum & 105.70 & 6.2 & 1.3 & 6.6 & 303.3 & 6.27 & 1.3 & 6.61 \\
\hline & & G.macrocarbium & 138.70 & 6.3 & 1.3 & 6.8 & 443.3 & 6.4 & 1.37 & 6.65 \\
\hline & & Mixture & 228.70 & 6.3 & 1.4 & 6.6 & 650.8 & 6.2 & 1.5 & 6.67 \\
\hline & \multirow[t]{4}{*}{1.5} & Control & 81.70 & 6.3 & 1.3 & 6.1 & 219.3 & 5.95 & 1.4 & 6.27 \\
\hline & & A.chrococcum & 117.35 & 6.4 & 1.3 & 6.8 & 338.3 & 6.53 & 1.29 & 6.92 \\
\hline & & G.macrocarbium & 150.35 & 6.4 & 1.3 & 6.9 & 496.8 & 6.53 & 1.43 & 6.93 \\
\hline & & Mixture & 274.70 & 6.4 & 1.5 & 6.9 & 757.5 & 6.77 & 1.53 & 7.1 \\
\hline \multirow[t]{16}{*}{3000} & \multirow[t]{4}{*}{0} & Control & 68.35 & 5.2 & 1.2 & 5.4 & 178.3 & 5.2 & 1.25 & 5.37 \\
\hline & & A.chrococcum & 76.65 & 5.8 & 1.3 & 5.8 & 188.3 & 5.83 & 1.29 & 5.87 \\
\hline & & G.macrocarbium & 79.35 & 5.9 & 1.1 & 5.9 & 221.8 & 5.93 & 1.3 & 5.94 \\
\hline & & Mixture & 111.65 & 5.9 & 1.3 & 5.9 & 303.3 & 5.93 & 1.36 & 5.81 \\
\hline & \multirow[t]{4}{*}{0.5} & Control & 73.00 & 5.7 & 1.2 & 5.7 & 182.5 & 5.54 & 1.26 & 5.92 \\
\hline & & A.chrococcum & 79.35 & 6 & 1.2 & 6.1 & 220.0 & 5.87 & 1.28 & 6.07 \\
\hline & & G.macrocarbium & 82.00 & 6.1 & 1.2 & 6.3 & 224.3 & 6.13 & 1.29 & 6.15 \\
\hline & & Mixture & 173.70 & 6.2 & 1.3 & 6.1 & 590.0 & 6.3 & 1.31 & 6.17 \\
\hline & \multirow[t]{4}{*}{1} & Control & 78.70 & 5.7 & 1.3 & 5.8 & 180.8 & 5.69 & 1.28 & 6.02 \\
\hline & & A.chrococcum & 81.30 & 6.1 & 1.2 & 6.3 & 235.0 & 6.1 & 1.27 & 6.27 \\
\hline & & G.macrocarbium & 87.30 & 6.2 & 1.2 & 6.7 & 252.5 & 6.13 & 1.28 & 6.28 \\
\hline & & Mixture & 199.30 & 6.2 & 1.4 & 6.4 & 605.8 & 6.47 & 1.37 & 6.57 \\
\hline & \multirow[t]{4}{*}{1.5} & Control & 89.70 & 5.9 & 1.3 & 6 & 212.5 & 5.93 & 1.29 & 6.25 \\
\hline & & A.chrococcum & 92.30 & 6.2 & 1.3 & 6.5 & 277.5 & 6.27 & 1.26 & 6.5 \\
\hline & & G.macrocarbium & 95.70 & 6.2 & 1.3 & 6.9 & 310.0 & 6.27 & 1.33 & 6.53 \\
\hline & & Mixture & 251.30 & 6.3 & 1.4 & 6.9 & 720.8 & 6.57 & 1.4 & 6.87 \\
\hline \multirow[t]{16}{*}{4000} & \multirow[t]{4}{*}{0} & Control & 62.00 & 5 & 1.1 & 5.3 & 167.5 & 4.9 & 1.17 & 5.35 \\
\hline & & A.chrococcum & 64.00 & 5.7 & 1.2 & 5.5 & 180.8 & 5.73 & 1.24 & 5.53 \\
\hline & & G.macrocarbium & 71.70 & 5.8 & 1.2 & 5.7 & 203.3 & 5.8 & 1.23 & 5.75 \\
\hline & & Mixture & 94.00 & 5.9 & 1.3 & 5.8 & 162.5 & 5.9 & 1.33 & 5.79 \\
\hline & \multirow[t]{4}{*}{0.5} & Control & 72.70 & 5.2 & 1.2 & 5.6 & 190.0 & 5.44 & 1.25 & 5.5 \\
\hline & & A.chrococcum & 72.70 & 5.8 & 1.2 & 5.8 & 191.8 & 5.87 & 1.23 & 5.83 \\
\hline & & G.macrocarbium & 75.70 & 5.9 & 1.2 & 6 & 210.8 & 5.93 & 1.24 & 5.89 \\
\hline & & Mixture & 93.70 & 6.1 & 1.3 & 6.1 & 244.3 & 6.19 & 1.29 & 6.05 \\
\hline & 1 & Control & 76.70 & 5.3 & 1.2 & 5.6 & 200.8 & 5.45 & 1.26 & 5.81 \\
\hline & & A.chrococcum & 78.00 & 6 & 1.2 & 6 & 217.5 & 6.13 & 1.2 & 6.07 \\
\hline & & G.macrocarbium & 82.00 & 5.9 & 1.2 & 6.2 & 230.8 & 5.87 & 1.27 & 5.93 \\
\hline & & Mixture & 119.30 & 6.2 & 1.4 & 6.4 & 331.8 & 6.23 & 1.37 & 6.2 \\
\hline & 1.5 & Control & 77.30 & 5.4 & 1.2 & 5.9 & 204.3 & 5.38 & 1.25 & 6.02 \\
\hline & & A.chrococcum & 86.00 & 6 & 1.3 & 6.1 & 236.8 & 6.17 & 1.18 & 6.1 \\
\hline & & G.macrocarbium & 92.30 & 6.2 & 1.3 & 6.2 & 280.8 & 6.23 & 1.32 & 6.03 \\
\hline & & Mixture & 124.00 & 6.3 & 1.4 & 6.8 & 393.3 & 6.33 & 1.4 & 6.43 \\
\hline L.S.D at & & & 1.939 & 0.064 & 0.97 & 0.064 & 0.043 & 0.07 & 2.30 & 0.0583 \\
\hline
\end{tabular}


Table 6. A specific effect of water irrigation Salinity, humic acid concentration and biofertilization treatments on a shoot and root system of olive seedling in the $2^{\text {nd }}$ season.

\begin{tabular}{|c|c|c|c|c|}
\hline \multirow[t]{2}{*}{ Treatment levels } & \multicolumn{4}{|c|}{$2^{\text {nd }}$ season } \\
\hline & $\begin{array}{c}\text { Shoot fresh weight } \\
\text { (g) }\end{array}$ & $\begin{array}{c}\text { Shoot dry weight } \\
\text { (g) }\end{array}$ & $\begin{array}{l}\text { Root fresh weight } \\
\text { (g) }\end{array}$ & $\begin{array}{l}\text { Root dry weight } \\
\text { (g) }\end{array}$ \\
\hline \multicolumn{5}{|c|}{ Salinity(ppm) } \\
\hline 2000 & 208.08 & 77.80 & 173.60 & 66.88 \\
\hline 3000 & 191.88 & 73.32 & 158.48 & 60.36 \\
\hline 4000 & 178.92 & 70.20 & 145.36 & 56.08 \\
\hline L.S.D at $5 \%$ & 1.02 & 0.06 & 0.95 & 0.43 \\
\hline \multicolumn{5}{|c|}{ Humic(ml/L) } \\
\hline 0 & 177.36 & 66.92 & 142.92 & 53.40 \\
\hline 0.5 & 185.44 & 69.04 & 152.96 & 56.56 \\
\hline 1.0 & 198.80 & 78.64 & 164.12 & 65.36 \\
\hline 1.5 & 210.40 & 80.48 & 176.64 & 69.00 \\
\hline L.S.D at $5 \%$ & 0.94 & 0.08 & 1.30 & 0.49 \\
\hline \multicolumn{5}{|c|}{ Biofertilization treatments } \\
\hline Control & 136.02 & 59.16 & 102.40 & 46.20 \\
\hline A.chrococcum & 195.72 & 69.36 & 162.40 & 56.80 \\
\hline G.macrocarbium & 208.80 & 78.44 & 175.12 & 66.40 \\
\hline Mixture & 231.60 & 88.12 & 196.84 & 75.00 \\
\hline L.S.D at $5 \%$ & 0.98 & 0.18 & 1.01 & 0.49 \\
\hline
\end{tabular}

As shown in Table 6 biofertilization treatments greatly affected the fresh and dry weight of seedling shoot and root system, Mixed treatments followed by single treatment with Myccorhizae than azotobacter recorded the highest value compared to control (without inoculation).

Concerning interaction effect on different salinity levels, three humic acid concentration and biofertilization treatments obtained results in Tables 7 clearly showed that, humic acid with Biofertilization treatment with different salinity levels enhanced fresh and dry weight of Olive seedling shoot and root system in the second season, the highest increment was recorded by humic acid at concentration(1.5) with mixed treatment at salinity level 2000 being $277.72 \mathrm{~g}$ and 106 $\mathrm{g}$ for fresh and dry shoot system weight respectively . While fresh and dry root system weight recorded 240.28 $\mathrm{g}$ and $91.72 \mathrm{~g}$ in the second season respectively.

Stimulating effect clearly appears between humic acid application and biofertilization treatments to mitigate salinity effects as shown by Magdi et al., (2011) they reported that biofertilization and humic acid could be used as a complementary for mineral fertilizers to improve yield and quality of cowpea.

\section{Macronutrients}

Table 8 indicated that the highest values of $\mathrm{N}, \mathrm{P}$ and $\mathrm{K}$ contents were attained by salinity level 2000 so, increasing salinity level decrease $\mathrm{N}, \mathrm{P}$ and $\mathrm{K}$ in Olive leaves, in addition, Macronutrients were also affected by different humic acid concentration increasing humic acid concentration lead to increasing the values of NPK in both studied seasons.

As shown in Table 8 biofertilization treatments greatly affected of the values of NPK, Mixed treatments followed by single treatment with Myccorhizae, azotobacter recorded the highest values in comparison with control (without inoculation) in both studied seasons.

As shown in Table 9 the interaction between mixed biofertilization and HA gave synergistic with the lowest level of salinity gave the highest values of $\mathrm{N}, \mathrm{P}$ and $\mathrm{K}$ being 208, 15.7 and $286 \mathrm{ppm}$ in the first season and $214,15.68$ and 291 in the second season, respectively.

Treatment with A.chroococcum and G.macrocarbium mitigated the adverse effect of salinity where Olive seedlings were able to grow and survive with the majority of treatments. Application of HA $(0.5,1$ and $1.5 \mathrm{ml} / \mathrm{L})$ alleviate the adverse effect of salinity on Olive seedlings. Enhancement of leaves contents of nutrients using humic acid had been noticed to be due to increased nutrients uptake such as $\mathrm{N}, \mathrm{P}, \mathrm{K}$, $\mathrm{Ca}, \mathrm{Mg}, \mathrm{Fe}, \mathrm{Zn}$ and $\mathrm{Cu}$ David et al., 1994. 
Table 7. Interaction effect of water irrigation Salinity, humic acid concentration and biofertilization treatments on shoot and root system weight of olive seedling in the $2^{\text {nd }}$ season

\begin{tabular}{|c|c|c|c|c|c|c|}
\hline \multirow[b]{2}{*}{ Salinity } & \multirow[b]{2}{*}{ Humic } & \multirow[b]{2}{*}{ Biofertilizers } & \multicolumn{4}{|c|}{$2^{\text {nd }}$ season } \\
\hline & & & $\begin{array}{c}\text { Shoot fresh } \\
\text { weight (g) }\end{array}$ & $\begin{array}{l}\text { Shoot dry } \\
\text { weight (g) }\end{array}$ & $\begin{array}{l}\text { Root fresh } \\
\text { weight (g) }\end{array}$ & $\begin{array}{c}\text { Root dry } \\
\text { weight (g) }\end{array}$ \\
\hline \multirow[t]{16}{*}{2000} & \multirow[t]{4}{*}{0} & Control & 126.28 & 48.2 & 92.52 & 35.32 \\
\hline & & A.chrococcum & 186.52 & 71.2 & 154.28 & 58.88 \\
\hline & & G.macrocarbium & 197.72 & 75.48 & 165.72 & 63.48 \\
\hline & & Mixture & 235.08 & 89.6 & 193.72 & 73.96 \\
\hline & \multirow[t]{4}{*}{0.5} & Control & 151.48 & 57.84 & 103.72 & 39.6 \\
\hline & & A.chrococcum & 193.88 & 74 & 165.32 & 63.12 \\
\hline & & G.macrocarbium & 206 & 78.64 & 176 & 67.16 \\
\hline & & Mixture & 249.6 & 95.28 & 216.8 & 82.76 \\
\hline & \multirow[t]{4}{*}{1} & Control & 198.4 & 75.6 & 113.08 & 43.16 \\
\hline & & A.chrococcum & 211.32 & 80.68 & 177.6 & 67.8 \\
\hline & & G.macrocarbium & 222.52 & 84.92 & 194.68 & 74.32 \\
\hline & & Mixture & 266.4 & 101.68 & 234 & 89.32 \\
\hline & \multirow[t]{4}{*}{1.5} & Control & 151.32 & 57.76 & 134.68 & 51.4 \\
\hline & & A.chrococcum & 151.72 & 57.92 & 194.52 & 74.24 \\
\hline & & G.macrocarbium & 234.68 & 89.6 & 202.4 & 77.24 \\
\hline & & Mixture & 277.72 & 106 & 240.28 & 91.72 \\
\hline \multirow[t]{16}{*}{3000} & \multirow[t]{4}{*}{0} & Control & 118.12 & 45.08 & 81.72 & 31.2 \\
\hline & & A.chrococcum & 190.12 & 72.56 & 146.8 & 56.04 \\
\hline & & G.macrocarbium & 190.8 & 72.84 & 154.52 & 58.96 \\
\hline & & Mixture & 210.4 & 80.32 & 179.48 & 68.52 \\
\hline & \multirow[t]{4}{*}{0.5} & Control & 126.12 & 48.12 & 94.68 & 36.12 \\
\hline & & A.chrococcum & 193.6 & 73.92 & 164.28 & 62.72 \\
\hline & & G.macrocarbium & 199.2 & 76.04 & 168.92 & 64.48 \\
\hline & & Mixture & 225.32 & 86 & 189.88 & 72.48 \\
\hline & \multirow[t]{4}{*}{1} & Control & 128.12 & 48.92 & 103.08 & 39.36 \\
\hline & & A.chrococcum & 201.72 & 77 & 166.12 & 63.4 \\
\hline & & G.macrocarbium & 210.8 & 80.48 & 183.2 & 69.92 \\
\hline & & Mixture & 243.6 & 92.96 & 201.6 & 76.96 \\
\hline & \multirow[t]{4}{*}{1.5} & Control & 146.4 & 55.88 & 113.72 & 43.4 \\
\hline & & A.chrococcum & 208 & 79.4 & 178.52 & 68.16 \\
\hline & & G.macrocarbium & 229.72 & 87.68 & 194.28 & 74.16 \\
\hline & & Mixture & 248.12 & 94.72 & 208.28 & 79.52 \\
\hline \multirow[t]{17}{*}{4000} & \multirow[t]{4}{*}{0} & Control & 114.4 & 43.68 & 74.28 & 28.36 \\
\hline & & A.chrococcum & 164.12 & 62.64 & 128.12 & 48.92 \\
\hline & & G.macrocarbium & 182.68 & 69.72 & 150.8 & 57.56 \\
\hline & & Mixture & 187.08 & 71.4 & 157.2 & 60 \\
\hline & \multirow[t]{4}{*}{0.5} & Control & 114.8 & 43.8 & 86.68 & 33.08 \\
\hline & & A.chrococcum & 170.12 & 48.2 & 143.32 & 35.32 \\
\hline & & G.macrocarbium & 197.6 & 71.2 & 159.48 & 58.88 \\
\hline & & Mixture & 198 & 75.48 & 166.4 & 63.28 \\
\hline & \multirow[t]{4}{*}{1} & Control & 131.2 & 89.72 & 98.12 & 73.96 \\
\hline & & A.chrococcum & 195.32 & 57.84 & 153.48 & 39.6 \\
\hline & & G.macrocarbium & 211.72 & 74 & 168.68 & 63.12 \\
\hline & & Mixture & 202.28 & 78.64 & 171.72 & 67.16 \\
\hline & \multirow[t]{5}{*}{1.5} & Control & 137.32 & 95.28 & 103.08 & 82.76 \\
\hline & & A.chrococcum & 202.12 & 75.72 & 166.92 & 43.16 \\
\hline & & G.macrocarbium & 221.48 & 80.68 & 182.8 & 67.8 \\
\hline & & Mixture & 233.88 & 84.92 & 186.8 & 74.32 \\
\hline & & L.S.D at $5 \%$ & 3.4116 & 0.3016 & 1.652 & 1.6876 \\
\hline
\end{tabular}


Table 8. Specific effects of salinity level, humic acid and biofertilization on macronutrients content at Olive rhizosphere at $2^{\text {nd }}$ seasons.

\begin{tabular}{|c|c|c|c|c|c|c|}
\hline \multirow[t]{2}{*}{ treatment } & \multicolumn{3}{|c|}{$1^{\text {st }}$ season } & \multicolumn{3}{|c|}{$2^{\text {nd }}$ season } \\
\hline & N ppm & P ppm & K ppm & N ppm & P ppm & K ppm \\
\hline \multicolumn{7}{|c|}{ Salinity (ppm) } \\
\hline 2000 & 178.4 & 13.3 & 250.8 & 181.7 & 13.4 & 256.3 \\
\hline 3000 & 174.1 & 12.6 & 245.6 & 177.9 & 13.1 & 249.8 \\
\hline 4000 & 171.2 & 12.6 & 233.9 & 174.4 & 12.74 & 239.1 \\
\hline L.S.D at $5 \%$ & 0.163 & 0.0407 & 0.149 & 0.615 & 0.068 & 0.1883 \\
\hline \multicolumn{7}{|c|}{ Humic (ml/L) } \\
\hline 0 & 170 & 12.7 & 235.3 & 173.1 & 12.84 & 238.8 \\
\hline 0.5 & 173.3 & 12.8 & 239.7 & 177 & 13.1 & 245.8 \\
\hline 1.0 & 176.3 & 13 & 244.6 & 179.5 & 13.12 & 250.5 \\
\hline 1.5 & 178.6 & 13.12 & 254.2 & 182.4 & 13.25 & 258.56 \\
\hline L.S.D at $5 \%$ & 0.158 & 0.049 & 0.194 & 0.7013 & 0.0137 & 0.2576 \\
\hline \multicolumn{7}{|c|}{ Biofertilization treatments } \\
\hline Control & 155.92 & 11.11 & 229.8 & 158 & 11.23 & 232.4 \\
\hline A.chrococcum & 185.33 & 11.98 & 237.6 & 188.8 & 12.1 & 243.4 \\
\hline G.macrocarbium & 163.1 & 13.93 & 248.1 & 166.2 & 14.2 & 253.3 \\
\hline Mixture & 193.9 & 14.6 & 258.4 & 199 & 14.8 & 264.5 \\
\hline L.S.D at $5 \%$ & 0.09 & 0.047 & 0.1268 & 0.556 & 0.115 & 0.2546 \\
\hline
\end{tabular}

These results agree with those of Pellerin et al., 2007 who concluded that mycorrhiza is capable of taking up, translocation and transferring water and nutrients because of the enlarged surface area of the roots zone. In the same trend, many investigators demonstrated that the positive effect of dual inoculation with $\mathrm{N}_{2}$-fixer and P-solubilizer.

In the same trend, many investigators demonstrated that the positive effect of dual inoculation with N2-fixer and P-solubilizer.

Table 10 showed that the microbial determination (Total microbial counts, Azotobacter densities, mycorrhizal infection $\%$ and Mycorrhizal spores) at rhizosphere of inoculated plants were recorded significant increases with salinity level 2000 and decrease with increasing salinity, HA concentrations $1.5 \%$ recorded the highest value for microbial determination. For Biofertilization treatments it was found that microbial determination recorded the highest value with mixed inoculation treatment compared with control These results incompatible with the finding of (El-Wakeil and El-Sebai, 2007) who reported that total microbial count was higher significantly in mixed inoculant's strains than in single inoculant.

It was clear from the data represented in Table 10 that inoculation with A.chroococcum and G.macrocarbium stimulated the activity and growth Total microbial counts, Azotobacter densities, mycorrhizal infection percentage and Mycorrhizal spores.
The interaction between salinity, humic acid concentrations and Biofertilization treatments were represented in Table 11 The highest total microbial counts were associated with first salinity level (2000 $\mathrm{ppm}$ ), humic acid $1.5 \%$ and mixed treatment (A.chroococcum and G.macrocarpium) being 190 and $211 \times 105 \mathrm{cfu} / \mathrm{g}$ dry soil at first and second seasons respectively. These results are compatible with those obtained by (Ashrafuzzaman et al., 2009) who reported that, inoculation with the plant growth promoting rhizobacteria like Azotobcter, had stimulation effect on the population of rhizosphere microorganisms and increased their numbers by more than $50 \%$ at the end of the experiment compared with the number recorded before planting.

\section{Soil Enzymatic Activity}

Soil enzymatic activity clearly affected with Salinity level, increasing salinity reduces enzymatic activity, while increasing humic acid concentration led to increased soil enzymatic activity. biofertilization treatment either single or mixed inoculation stimulate soil enzymes especially mixed inoculation. Dehydrogenase, Nitrogenase and phosphatase enzymes were measured to clarify the effect of the different used biofertilization treatments and humic acid concentrations on soil enzymatic activity. Soil enzymes varied within the different biofertilization treatments and HA levels. Azotobacter chroococcum inoculation as single treatment gave the higher values of soil enzymes than Mycorrhizae, while, mixed biofertilization 
Table 9. Interaction effects of salinity, humic acid and biofertilization on macronutrients content at Olive rhizosphere at $2^{\text {nd }}$ seasons.

\begin{tabular}{|c|c|c|c|c|c|c|c|c|}
\hline \multirow[b]{2}{*}{$\begin{array}{l}\text { Salinity } \\
\text { ppm }\end{array}$} & \multirow[b]{2}{*}{$\begin{array}{l}\text { Humic } \\
\mathrm{ml} / \mathrm{L}\end{array}$} & \multirow[b]{2}{*}{$\begin{array}{l}\text { Biofertilization } \\
\text { treatments }\end{array}$} & \multicolumn{3}{|c|}{$1^{\text {st }}$ season } & \multicolumn{3}{|c|}{$2^{\text {nd }}$ season } \\
\hline & & & $\begin{array}{c}\mathbf{N} \\
\mathbf{p p m}\end{array}$ & $\begin{array}{c}\mathbf{P} \\
\mathbf{p p m}\end{array}$ & $\begin{array}{c}\mathbf{K} \\
\mathbf{p p m}\end{array}$ & $\begin{array}{c}\mathbf{N} \\
\mathbf{p p m}\end{array}$ & $\begin{array}{c}\mathbf{P} \\
\mathbf{p p m}\end{array}$ & $\begin{array}{c}\mathbf{K} \\
\mathbf{p p m}\end{array}$ \\
\hline \multirow[t]{16}{*}{2000} & \multirow[t]{4}{*}{0} & Control & 159 & 11.1 & 228 & 162 & 11.16 & 231 \\
\hline & & A.chrococcum & 182 & 12.15 & 236 & 186 & 12.24 & 239 \\
\hline & & G.macrocarbium & 160 & 14.23 & 243 & 161 & 14.36 & 245 \\
\hline & & Mixture & 193 & 14.94 & 251 & 197 & 15.21 & 255 \\
\hline & \multirow[t]{4}{*}{0.5} & Control & 159 & 11.12 & 231 & 162 & 11.19 & 255 \\
\hline & & A.chrococcum & 184 & 12.26 & 239 & 187 & 12.34 & 242 \\
\hline & & G.macrocarbium & 168 & 14.36 & 248 & 169 & 14.46 & 251 \\
\hline & & Mixture & 194 & 15.12 & 257 & 198 & 15.34 & 264 \\
\hline & \multirow[t]{4}{*}{1} & Control & 160 & 11.26 & 237 & 164 & 11.2 & 239 \\
\hline & & A.chrococcum & 192 & 12.71 & 246 & 198 & 12.42 & 249 \\
\hline & & G.macrocarbium & 169 & 14.4 & 261 & 171 & 14.52 & 268 \\
\hline & & Mixture & 196 & 15.3 & 278 & 203 & 15.43 & 286 \\
\hline & \multirow[t]{4}{*}{1.5} & Control & 163 & 11.3 & 241 & 165 & 11.21 & 244 \\
\hline & & A.chrococcum & 195 & 12.76 & 258 & 206 & 12.53 & 263 \\
\hline & & G.macrocarbium & 172 & 14.9 & 273 & 173 & 14.53 & 278 \\
\hline & & Mixture & 208 & 15.7 & 286 & 214 & 15.68 & 291 \\
\hline \multirow[t]{16}{*}{3000} & \multirow[t]{4}{*}{0} & Control & 152 & 10.93 & 225 & 153 & 11.05 & 228 \\
\hline & & A.chrococcum & 179 & 11.69 & 234 & 184 & 11.75 & 238 \\
\hline & & G.macrocarbium & 158 & 13.9 & 239 & 162 & 14.2 & 242 \\
\hline & & Mixture & 189 & 14.12 & 248 & 193 & 14.24 & 251 \\
\hline & \multirow[t]{4}{*}{0.5} & Control & 155 & 11.15 & 228 & 158 & 11.19 & 231 \\
\hline & & A.chrococcum & 184 & 11.94 & 238 & 188 & 12.04 & 242 \\
\hline & & G.macrocarbium & 163 & 13.78 & 246 & 171 & 14.29 & 253 \\
\hline & & Mixture & 191 & 14.26 & 257 & 193 & 14.58 & 264 \\
\hline & \multirow[t]{4}{*}{1} & Control & 155 & 11.15 & 229 & 156 & 11.23 & 232 \\
\hline & & A.chrococcum & 188 & 11.98 & 241 & 192 & 12.2 & 243 \\
\hline & & G.macrocarbium & 165 & 13.85 & 253 & 171 & 14.36 & 258 \\
\hline & & Mixture & 198 & 14.61 & 260 & 202 & 14.82 & 271 \\
\hline & \multirow[t]{4}{*}{1.5} & Control & 158 & 11.16 & 230 & 160 & 11.29 & 234 \\
\hline & & A.chrococcum & 188 & 12.1 & 249 & 191 & 12.36 & 256 \\
\hline & & G.macrocarbium & 165 & 14.26 & 268 & 167 & 14.49 & 258 \\
\hline & & Mixture & 197 & 14.69 & 284 & 205 & 14.95 & 296 \\
\hline \multirow[t]{16}{*}{4000} & \multirow[t]{4}{*}{0} & Control & 149 & 10.82 & 219 & 149 & 10.96 & 223 \\
\hline & & A.chrococcum & 178 & 11.45 & 227 & 182 & 11.58 & 231 \\
\hline & & G.macrocarbium & 156 & 13.28 & 235 & 158 & 13.45 & 239 \\
\hline & & Mixture & 185 & 13.71 & 239 & 189 & 13.96 & 243 \\
\hline & \multirow[t]{4}{*}{0.5} & Control & 153 & 11 & 220 & 155 & 11.06 & 225 \\
\hline & & A.chrococcum & 183 & 11.65 & 231 & 187 & 11.82 & 236 \\
\hline & & G.macrocarbium & 158 & 13.6 & 236 & 162 & 13.75 & 239 \\
\hline & & Mixture & 188 & 13.94 & 245 & 195 & 14.11 & 248 \\
\hline & \multirow[t]{4}{*}{1} & Control & 154 & 11.12 & 220 & 156 & 11.15 & 224 \\
\hline & & A.chrococcum & 184 & 11.72 & 236 & 189 & 11.86 & 237 \\
\hline & & G.macrocarbium & 161 & 13.46 & 243 & 165 & 13.89 & 248 \\
\hline & & Mixture & 193 & 14.1 & 249 & 197 & 14.36 & 251 \\
\hline & 1.5 & Control & 154 & 11.25 & 221 & 155 & 11.34 & 223 \\
\hline & & A.chrococcum & 185 & 11.96 & 239 & 186 & 12.08 & 245 \\
\hline & & G.macrocarbium & 162 & 13.78 & 248 & 165 & 13.97 & 261 \\
\hline & & Mixture & 194 & 14.26 & 252 & 201 & 14.52 & 253 \\
\hline L.S.,D,at & & & 0.6509 & 0.1627 & 0.5971 & 0.4613 & 0.0187 & 0.6236 \\
\hline
\end{tabular}


Table 10. Main effects of salinity, humic acid and biofertilization on Microbial determinations in Olive rhizosphere at two growing seasons.

\begin{tabular}{|c|c|c|c|c|c|c|c|c|}
\hline \multirow{2}{*}{ Treatment } & \multicolumn{4}{|c|}{ 1st season } & \multicolumn{4}{|c|}{ 2nd season } \\
\hline & Tc & $\mathbf{A z}$ & М\% & Spore no. & Tc & $\mathbf{A z}$ & M\% & Spoe \\
\hline \multicolumn{9}{|c|}{ Salinity (ppm) } \\
\hline 2000 & 131.19 & 79.5 & 15.66 & 11.66 & 137.08 & 80.68 & 13.82 & 11.88 \\
\hline 3000 & 92.88 & 585 & 13.3 & 10.96 & 97.92 & 59.77 & 13.9 & 11.43 \\
\hline 4000 & 81.25 & 46.81 & 13.26 & 10.04 & 89.19 & 4958 & 16.7 & 10.5 \\
\hline L.S.D at $5 \%$ & 0.209945 & 0.1680 & 0.0307 & 0.0162 & 0.1382 & 0.1478 & 0.0441 & 0.0261 \\
\hline \multicolumn{9}{|c|}{ Humic $(\mathrm{ml} / \mathrm{L})$} \\
\hline 0 & 93.67 & 55.08 & 13 & 10.43 & 97.94 & 57.92 & 13.68 & 10.8 \\
\hline 0.5 & 97.92 & 60.58 & 13.8 & 10.72 & 104.17 & 62.4 & 14.52 & 10.85 \\
\hline 1.0 & 103.67 & 62.58 & 14.5 & 11.08 & 111.17 & 65.8 & 15.19 & 11.4 \\
\hline 1.5 & 111.83 & 65.5 & 14.97 & 11.33 & 118.97 & 67.33 & 15.75 & 12.04 \\
\hline L.S.D at $5 \%$ & 0.26284 & 0.2357 & 0.0299 & 0.0208 & 0.2069 & 0.1099 & 0.0453 & 0.0218 \\
\hline \multicolumn{9}{|c|}{ Biofertilization treatments } \\
\hline Control & 70.42 & 41.83 & 6.4 & 8.6 & 72.83 & 45.64 & 6.85 & 8.6 \\
\hline A.chrococcum & 97.42 & 51 & 7.43 & 9.06 & 103.44 & 53.11 & 7.91 & 10.13 \\
\hline G.macrocarbium & 109.75 & 71.5 & 20.56 & 12.77 & 117.11 & 72.44 & 21.34 & 12.9 \\
\hline Mixture & 129.5 & 78.92 & 21.92 & 13.15 & 138.86 & 82.19 & 22.98 & 13.21 \\
\hline L.S.D at $5 \%$ & 0.1242 & 0.2477 & 0.0280 & 0.0142 & 0.1021 & 0.1620 & 0.0451 & 0.0256 \\
\hline
\end{tabular}

Table 11. Interaction effect of salinity, humic acid and biofertilization on Microbial determinations in Olive rhizosphere at two growing seasons.

\begin{tabular}{|c|c|c|c|c|c|c|c|c|c|c|}
\hline \multirow[b]{2}{*}{$\begin{array}{c}\text { Salinity } \\
\text { ppm }\end{array}$} & \multirow[b]{2}{*}{$\underset{\mathrm{ml} / \mathrm{L}}{\mathrm{Humic}}$} & \multirow[b]{2}{*}{$\begin{array}{l}\text { Biofertilization } \\
\text { treatments }\end{array}$} & \multicolumn{4}{|c|}{$1^{\text {st }}$ season } & \multicolumn{4}{|c|}{$2^{\text {nd }}$ season } \\
\hline & & & Tc & $\mathbf{A z}$ & M\% & $\begin{array}{c}\text { M } \\
\text { spore }\end{array}$ & Tc & $\mathbf{A z}$ & M\% & $\begin{array}{c}\text { M } \\
\text { spore }\end{array}$ \\
\hline \multirow[t]{16}{*}{2000} & \multirow[t]{4}{*}{0} & Control & 74 & 47 & 6.8 & 8.9 & 76 & 53 & 7.2 & 9.3 \\
\hline & & A.chrococcum & 118 & 83 & 8.2 & 9.2 & 122 & 85 & 8.8 & 9.8 \\
\hline & & G.macrocarbium & 132 & 62 & 20.8 & 12.8 & 139 & 63 & 21.3 & 13.3 \\
\hline & & Mixture & 159 & 94 & 22.1 & 13.2 & 164 & 97 & 22.9 & 13.7 \\
\hline & \multirow[t]{4}{*}{0.5} & Control & 77 & 52 & 7.5 & 9.1 & 79 & 53 & 7.9 & 9.4 \\
\hline & & A.chrococcum & 123 & 93 & 8.9 & 9.3 & 130 & 88 & 9.5 & 9.9 \\
\hline & & G.macrocarbium & 141 & 68 & 21.6 & 13.4 & 148 & 65 & 23.1 & 13.7 \\
\hline & & Mixture & 170 & 106 & 24.1 & 13.7 & 173 & 110 & 25.6 & 13.8 \\
\hline & \multirow[t]{4}{*}{1} & Control & 78 & 48 & 7.6 & 9.3 & 85 & 58 & 8.1 & 9.5 \\
\hline & & A.chrococcum & 129 & 97 & 9.2 & 9.7 & 133 & 93 & 9.6 & 9.8 \\
\hline & & G.macrocarbium & 148 & 70 & 22.4 & 14.2 & 156 & 69 & 23.9 & 14.4 \\
\hline & & Mixture & 184 & 112 & 24.8 & 14.8 & 179 & 114 & 27.1 & 14.9 \\
\hline & \multirow[t]{4}{*}{1.5} & Control & 86 & 50 & 7.9 & 9.5 & 89 & 59 & 8.6 & 9.6 \\
\hline & & A.chrococcum & 136 & 102 & 9.8 & 9.8 & 147 & 98 & 10.3 & 10.1 \\
\hline & & G.macrocarbium & 152 & 71 & 23.6 & 14.7 & 162 & 71 & 24.9 & 14.9 \\
\hline & & Mixture & 190 & 118 & 25.2 & 14.9 & 211 & 115 & 27.6 & 15.6 \\
\hline \multirow[t]{16}{*}{3000} & \multirow[t]{4}{*}{0} & Control & 63 & 38 & 5.7 & 8.3 & 66 & 42 & 5.9 & 8.6 \\
\hline & & A.chrococcum & 76 & 60 & 6.2 & 8.9 & 81 & 61 & 6.7 & 9.2 \\
\hline & & G.macrocarbium & 85 & 44 & 18.9 & 12.5 & 89 & 47 & 19.3 & 13.1 \\
\hline & & Mixture & 104 & 63 & 19.3 & 12.9 & 113 & 69 & 19.8 & 13.4 \\
\hline & \multirow[t]{4}{*}{0.5} & Control & 68 & 43 & 5.7 & 8.7 & 71 & 44 & 6.2 & 8.8 \\
\hline & & A.chrococcum & 78 & 64 & 6.4 & 9.1 & 86 & 67 & 6.8 & 9.3 \\
\hline & & G.macrocarbium & 92 & 49 & 19.5 & 12.8 & 98 & 50 & 20.1 & 13.5 \\
\hline & & Mixture & 106 & 71 & 20.7 & 13.1 & 113 & 78 & 21.2 & 13.9 \\
\hline & \multirow[t]{4}{*}{1} & Control & 69 & 42 & 5.9 & 8.8 & 72 & 45 & 6.5 & 9.2 \\
\hline & & A.chrococcum & 95 & 69 & 6.7 & 9.3 & 103 & 73 & 7.3 & 9.8 \\
\hline & & G.macrocarbium & 98 & 47 & 20.3 & 12.9 & 114 & 52 & 20.6 & 13.7 \\
\hline & & Mixture & 113 & 74 & 21.8 & 13.2 & 121 & 79 & 22.4 & 14.2 \\
\hline & \multirow[t]{4}{*}{1.5} & Control & 70 & 46 & 6.1 & 8.9 & 71 & 46 & 6.9 & 9.1 \\
\hline & & A.chrococcum & 106 & 71 & 6.9 & 9.4 & 109 & 73 & 7.4 & 9.7 \\
\hline & & G.macrocarbium & 119 & 48 & 20.8 & 13.1 & 122 & 52 & 21.5 & 13.4 \\
\hline & & Mixture & 128 & 77 & 21.9 & 13.5 & 138 & 79 & 22.4 & 13.9 \\
\hline
\end{tabular}


Table 11. Interaction effect of salinity, humic acid and biofertilization on Microbial determinations in Olive rhizosphere at two growing seasons.

\begin{tabular}{|c|c|c|c|c|c|c|c|c|c|c|}
\hline \multirow[b]{2}{*}{$\begin{array}{c}\text { Salinity } \\
\text { ppm }\end{array}$} & \multirow[b]{2}{*}{$\begin{array}{c}\text { Humic } \\
\mathrm{ml} / \mathrm{L}\end{array}$} & \multirow[b]{2}{*}{$\begin{array}{l}\text { Biofertilization } \\
\text { treatments }\end{array}$} & \multicolumn{4}{|c|}{$1^{\text {st }}$ season } & \multicolumn{4}{|c|}{$2^{\text {nd }}$ season } \\
\hline & & & Tc & $\mathbf{A z}$ & M\% & $\begin{array}{c}\text { M } \\
\text { spore }\end{array}$ & Tc & $\mathbf{A z}$ & M\% & $\begin{array}{c}\text { M } \\
\text { spore }\end{array}$ \\
\hline \multirow[t]{16}{*}{4000} & \multirow[t]{4}{*}{0} & Control & 59 & 33 & 5.3 & 7.5 & 64 & 34 & 5.7 & 7.6 \\
\hline & & A.chrococcum & 72 & 48 & 5.9 & 8.3 & 77 & 51 & 6.3 & 8.8 \\
\hline & & G.macrocarbium & 82 & 37 & 18.2 & 11.2 & 89 & 38 & 19.7 & 11.5 \\
\hline & & Mixture & 93 & 52 & 18.7 & 11.4 & 95 & 56 & 20.5 & 11.9 \\
\hline & \multirow[t]{4}{*}{0.5} & Control & 61 & 33 & 5.8 & 7.7 & 63 & 37 & 6.1 & 7.8 \\
\hline & & A.chrococcum & 75 & 54 & 6.4 & 8.4 & 78 & 55 & 6.9 & 9.1 \\
\hline & & G.macrocarbium & 87 & 39 & 19.2 & 11.5 & 94 & 43 & 19.8 & 12.1 \\
\hline & & Mixture & 97 & 57 & 20.1 & 11.9 & 109 & 59 & 20.8 & 12.7 \\
\hline & \multirow[t]{4}{*}{1} & Control & 61 & 35 & 6 & 7.9 & 67 & 38 & 6.3 & 8.3 \\
\hline & & A.chrococcum & 77 & 58 & 7.1 & 8.5 & 81 & 62 & 7.5 & 8.8 \\
\hline & & G.macrocarbium & 88 & 40 & 20.6 & 11.9 & 94 & 43 & 20.9 & 12.6 \\
\hline & & Mixture & 102 & 59 & 21.4 & 12.4 & 117 & 63 & 21.8 & 13.2 \\
\hline & \multirow[t]{4}{*}{1.5} & Control & 65 & 36 & 6.2 & 8.1 & 69 & 38 & 6.5 & 8.4 \\
\hline & & A.chrococcum & 83 & 61 & 7.5 & 8.8 & 88 & 64 & 7.6 & 9.1 \\
\hline & & G.macrocarbium & 91 & 43 & 20.9 & 12.3 & 97 & 45 & 21.5 & 12.8 \\
\hline & & Mixture & 107 & 64 & 22.9 & 12.8 & 125 & 69 & 23.6 & 13.4 \\
\hline \multicolumn{3}{|c|}{ L.S..D at $5 \%$} & 0.83 .75 & 0.6719 & 0.1229 & 0.065 & 0.553 & 0.5912 & 0.1765 & 0.1044 \\
\hline
\end{tabular}

TC: Total microbial counts $\times 10^{5} \mathrm{cfu} / \mathrm{g}$ soil, Az:Azotobacter densities $\times 10^{3} \mathrm{cells} / \mathrm{g}$ soil,M\%: Mycorrhizal infection \%, M Spore :

Number of mycorrhizal spores

Table 12. Main effects of salinity, humic acid and biofertilization on microbial enzymes activities in rhizosphere of Olive in the two growing seasons.

\begin{tabular}{|c|c|c|c|c|c|c|}
\hline \multirow[t]{2}{*}{ treatment } & \multicolumn{3}{|c|}{$1^{\text {st }}$ season } & \multicolumn{3}{|c|}{$2^{\text {nd }}$ season } \\
\hline & $\begin{array}{c}\text { Dehydrogenase } \\
\mu \mathrm{IDHA} / \mathrm{g} \text { dry } \\
\text { soil }\end{array}$ & $\begin{array}{c}\text { Nitrogenase } \\
\mu \mathrm{MC} 2 \mathrm{H} 4 \mathrm{~kg} / \mathrm{h}\end{array}$ & $\begin{array}{c}\text { Phosphatase } \\
\text { mg phenol/g } \\
\text { soil/24h }\end{array}$ & $\begin{array}{c}\text { Dehydrogenase } \\
\mu \mathrm{IDHA} / \mathrm{g} \text { dry } \\
\text { soil }\end{array}$ & $\begin{array}{l}\text { Nitrogenase } \\
\mu \mathrm{MC} 2 \mathrm{H} 4 \mathrm{~kg} / \mathrm{h}\end{array}$ & $\begin{array}{c}\text { Phosphatase } \\
\text { mg phenol/g } \\
\text { soil/24h }\end{array}$ \\
\hline \multicolumn{7}{|c|}{ Salinity(ppm) } \\
\hline 2000 & 1.99 & 0.37 & 0.17 & 2.03 & 0.39 & 0.18 \\
\hline 3000 & 1.84 & 0.32 & 0.15 & 1.89 & 0.38 & 0.16 \\
\hline 4000 & 1.76 & 0.27 & 0.14 & 1.82 & 0.29 & 0.14 \\
\hline L.S.D at $5 \%$ & 0.0186 & 0.47 & 0.07 & 0.832 & 0.0107 & 0.0107 \\
\hline \multicolumn{7}{|c|}{ Humic (ml/L) } \\
\hline 0 & 1.79 & 0.27 & 0.14 & 1.83 & 0.32 & 0.15 \\
\hline 0.5 & 1.85 & 0.29 & 0.15 & 1.91 & 0.34 & 0.16 \\
\hline 1.0 & 1.88 & 0.33 & 0.16 & 1.92 & 0.37 & 0.17 \\
\hline 1.5 & 1.93 & 0.36 & 0.17 & 1.98 & 0.402 & 0.18 \\
\hline L.S.D at $5 \%$ & 0.0198 & 0.077 & 0.0102 & 0.104 & 0.171 & 0.114 \\
\hline \multicolumn{7}{|c|}{ Biofertilization treatments } \\
\hline Control & 1.74 & 0.22 & 0.097 & 1.77 & 0.25 & 0.106 \\
\hline A.chrococcum & 1.82 & 0.35 & 0.14 & 1.88 & 0.4 & 0.151 \\
\hline G.macrocarbium & 1.93 & 0.3 & 0.17 & 1.97 & 0.33 & 0.183 \\
\hline Mixture & 1.97 & 0.39 & 0.2 & 2.02 & 0.45 & 0.21 \\
\hline L.S.D at $5 \%$ & 0.0153 & 0.013 & 0.018 & 0.168 & 0.0178 & 0.0137 \\
\hline
\end{tabular}


Table 13. Interaction effects of salinity, humic acid and biofertilization on microbial enzymes activities in rhizosphere of Olive in the two growing seasons.

\begin{tabular}{|c|c|c|c|c|c|c|c|c|}
\hline \multirow[b]{2}{*}{$\begin{array}{c}\text { Salinity } \\
\text { ppm }\end{array}$} & \multirow[b]{2}{*}{$\begin{array}{c}\text { Humic } \\
\mathrm{ml} / \mathrm{L}\end{array}$} & \multirow[b]{2}{*}{$\begin{array}{l}\text { Biofertilization } \\
\text { treatments }\end{array}$} & \multicolumn{3}{|c|}{$1^{\text {st }}$ season } & \multicolumn{3}{|c|}{$2^{\text {nd }}$ season } \\
\hline & & & $\begin{array}{c}\text { Dehydrogenase } \\
\mu \mathrm{IDHA} / \mathrm{g} \text { dry } \\
\text { soil }\end{array}$ & $\begin{array}{c}\text { Nitrogenase } \\
\mu \mathrm{MC} 2 \mathrm{H} 4 \mathrm{~kg} / \mathrm{h}\end{array}$ & $\begin{array}{c}\text { Phosphatase } \\
\text { mg phenol/g } \\
\text { soil/24h }\end{array}$ & $\begin{array}{c}\text { Dehydrogenase } \\
\mu \mathrm{IDHA} / \mathrm{g} \text { dry } \\
\text { soil }\end{array}$ & $\begin{array}{c}\text { Nitrogenase } \\
\mu \mathrm{MC} 2 \mathrm{H} 4 \mathrm{~kg} / \mathrm{h}\end{array}$ & $\begin{array}{c}\text { Phosphatase } \\
\text { mg phenol/g } \\
\text { soil/24h }\end{array}$ \\
\hline \multirow[t]{16}{*}{2000} & \multirow[t]{4}{*}{0} & Control & 1.78 & 0.22 & 0.096 & 1.81 & 0.25 & 0.11 \\
\hline & & A.chrococcum & 1.82 & 0.37 & 0.14 & 1.88 & 0.41 & 0.15 \\
\hline & & G.macrocarbium & 1.89 & 0.31 & 0.18 & 1.9 & 0.33 & 0.19 \\
\hline & & Mixture & 1.94 & 0.39 & 0.19 & 1.95 & 0.45 & 0.21 \\
\hline & \multirow[t]{4}{*}{0.5} & Control & 1.83 & 0.25 & 0.1 & 1.84 & 0.28 & 0.12 \\
\hline & & A.chrococcum & 1.96 & 0.38 & 0.16 & 1.98 & 0.46 & 0.16 \\
\hline & & G.macrocarbium & 2.02 & 0.34 & 0.18 & 2.06 & 0.36 & 0.2 \\
\hline & & Mixture & 2.14 & 0.41 & 0.21 & 2.15 & 0.47 & 0.22 \\
\hline & \multirow[t]{4}{*}{1} & Control & 1.89 & 0.27 & 0.11 & 1.9 & 0.28 & 0.13 \\
\hline & & A.chrococcum & 2.01 & 0.48 & 0.17 & 2.05 & 0.48 & 0.18 \\
\hline & & G.macrocarbium & 2.12 & 0.39 & 0.19 & 2.16 & 0.39 & 0.21 \\
\hline & & Mixture & 2.18 & 0.44 & 0.22 & 2.21 & 0.48 & 0.23 \\
\hline & \multirow[t]{4}{*}{1.5} & Control & 1.9 & 0.27 & 0.11 & 1.92 & 0.3 & 0.13 \\
\hline & & A.chrococcum & 2.08 & 0.51 & 0.19 & 2.15 & 0.53 & 0.18 \\
\hline & & G.macrocarbium & 2.19 & 0.43 & 0.2 & 2.24 & 0.44 & 0.22 \\
\hline & & Mixture & 2.25 & 0.49 & 0.23 & 2.29 & 0.56 & 0.24 \\
\hline \multirow[t]{16}{*}{3000} & \multirow[t]{4}{*}{0} & Control & 1.66 & 0.21 & 0.09 & 1.69 & 0.23 & 0.093 \\
\hline & & A.chrococcum & 1.78 & 0.28 & 0.13 & 1.82 & 0.38 & 0.15 \\
\hline & & G.macrocarbium & 1.86 & 0.23 & 0.15 & 1.88 & 0.31 & 0.16 \\
\hline & & Mixture & 1.88 & 0.34 & 0.17 & 1.93 & 0.42 & 0.19 \\
\hline & \multirow[t]{4}{*}{0.5} & Control & 1.7 & 0.22 & 0.095 & 1.71 & 0.26 & 0.1 \\
\hline & & A.chrococcum & 1.74 & 0.31 & 0.14 & 1.96 & 0.42 & 0.15 \\
\hline & & G.macrocarbium & 1.91 & 0.28 & 0.17 & 1.98 & 0.36 & 0.18 \\
\hline & & Mixture & 1.93 & 0.39 & 0.19 & 2.05 & 0.45 & 0.2 \\
\hline & \multirow[t]{4}{*}{1} & Control & 1.72 & 0.22 & 0.1 & 1.73 & 0.26 & 0.11 \\
\hline & & A.chrococcum & 1.75 & 0.34 & 0.15 & 1.78 & 0.44 & 0.16 \\
\hline & & G.macrocarbium & 1.93 & 0.31 & 0.18 & 1.99 & 0.37 & 0.19 \\
\hline & & Mixture & 1.98 & 0.45 & 0.2 & 2.03 & 0.48 & 0.21 \\
\hline & \multirow[t]{4}{*}{1.5} & Control & 1.77 & 0.24 & 0.1 & 1.78 & 0.28 & 0.11 \\
\hline & & A.chrococcum & 1.82 & 0.39 & 0.16 & 1.89 & 0.47 & 0.18 \\
\hline & & G.macrocarbium & 1.97 & 0.35 & 0.19 & 1.98 & 0.4 & 0.19 \\
\hline & & Mixture & 2.03 & 0.48 & 0.21 & 2.11 & 0.54 & 0.22 \\
\hline \multirow[t]{16}{*}{4000} & \multirow[t]{4}{*}{0} & Control & 1.63 & 0.18 & 0.082 & 1.68 & 0.21 & 0.086 \\
\hline & & A.chrococcum & 1.72 & 0.25 & 0.11 & 1.75 & 0.27 & 0.12 \\
\hline & & G.macrocarbium & 1.79 & 0.21 & 0.14 & 1.86 & 0.22 & 0.15 \\
\hline & & Mixture & 1.8 & 0.29 & 0.17 & 1.82 & 0.31 & 0.19 \\
\hline & \multirow[t]{4}{*}{0.5} & Control & 1.64 & 0.18 & 0.088 & 1.73 & 0.2 & 0.09 \\
\hline & & A.chrococcum & 1.72 & 0.27 & 0.11 & 1.79 & 0.29 & 0.12 \\
\hline & & G.macrocarbium & 1.8 & 0.23 & 0.15 & 1.86 & 0.25 & 0.16 \\
\hline & & Mixture & 1.82 & 0.33 & 0.19 & 1.82 & 0.34 & 0.2 \\
\hline & \multirow[t]{4}{*}{1} & Control & 1.66 & 0.19 & 0.09 & 1.69 & 0.2 & 0.094 \\
\hline & & A.chrococcum & 1.73 & 0.28 & 0.12 & 1.78 & 0.31 & 0.13 \\
\hline & & G.macrocarbium & 1.81 & 0.27 & 0.15 & 1.88 & 0.28 & 0.16 \\
\hline & & Mixture & 1.84 & 0.36 & 0.19 & 1.89 & 0.42 & 0.2 \\
\hline & 1.5 & Control & 1.69 & 0.2 & 0.096 & 1.76 & 0.21 & 0.1 \\
\hline & & A.chrococcum & 1.75 & 0.34 & 0.13 & 1.78 & 0.35 & 0.15 \\
\hline & & G.macrocarbium & 1.87 & 0.29 & 0.17 & 1.94 & 0.3 & 0.19 \\
\hline & & Mixture & 1.89 & 0.39 & 0.2 & 2.01 & 0.44 & 0.21 \\
\hline L.S.,D,at & $5 \%$ & & 0.0371 & 0.0186 & 0.0191 & 0.0177 & 0.0206 & 0.0260 \\
\hline
\end{tabular}


treatment surpassed all individual treatments. Many investigators demonstrated the positive effect of dual

Also, the addition of biofertilization treatments and HA level had a pronounced positive action on the quality of nitrogenase and phosphatase enzymes in both growing seasons. All biofertilization treatments improved the microbial activity in the rhizosphere zone and recorded significant increases, compared to the uninoculated treatment. These increases may be due to production of phytohormones such as Indoleacetic acid (IAA),gibberellic acid, cytokinins and ethylene (Glick, 1995), a symbiotic $\mathrm{N}_{2}$ fixation (Dobbelaera et al., 2003), antagonism against phytopathogenic microorganisms by production of siderophores (Scher and Baker, 1982), solubilization of mineral phosphates and other nutrients (De Freitas et al., 1997).

\section{CONCLUSION}

Biofertilization and humic acid application have the potential to improve Olive (Picual) seedling growth under salinity stress. Mixed biofertilization treatments showed synergistic effect toward elevate salinity stress on Olive seedlings and improve growth parameters. Humic acid application has a beneficial effect not only to plant growth and soil but to biofertilizers applied as well. Finally from this study we can concluded that Olive (Picual) seedling achieved the highest values in all studied parameter under salinity $2000 \mathrm{ppm}$ plus humic acid $1.5 \%$ with, Azotobacter chroococcum and Myccorhizae as mixed biofertilization treatment.

\section{REFERENCES}

Ashrafuzzaman, M., A. H. R. I. M.Farid, H. M. d.Anamul, I. S. M.Zahurul, Shahidullah, and S. Meon. 2009. Efficiency of plant growth-promoting rhizobacteria (PGPR) for the enhancement of rice S. M. growth. African J. of Biotechnol, 8 (7): 1247-1252.

Augé, R.M. 2001.Water relations, drought and vesiculararbuscular mycorrhizal symbiosis. Mycorrhiza 11:342.doi:10.1007/s005720100097

Becking, J.H. 2006. The Family Azotobacteraceae. In: Dworkin M., Schleifer Falkow S., Rosenberg E., Schleifer K.-H. and Stackebrandt E. The Prokaryotes, Vol. 6, 3rd edition. Singapore: Springer Science + Business Media.759 - 78 .

Berg, G. 2009. Plant-microbe interactions promoting plant growth and health: perspectives for controlled use of microorganisms in agriculture. Appl Microbiol Biotechnol 84:11-18. doi:10.1007/s00253-009-20 92-7

Canbolat, M., S. Bilen, R. Çakmakçı, F. Şahin and A. Aydın. 2006. Effect of plant growth-promoting bacteria and soil compaction on barley seedling growth, nutrient uptake, soil properties and rhizosphere microflora. Biol Fertil Soils 42:350-357. doi:10.1007/s00374-005-0034-9 inoculation with $\mathrm{N}_{2}$-fixer and P-solubilizes on $\mathrm{N}_{2}$-ase activity (El- Komy, 2005).

Chen, Y., M. De Nobili and T. Aviad, 2004. Stimulatory Effects of Humic Substances on Plant

David, P.P., P.V. Nelson and D.C. Sanders.1994.A humic acid improves growth of tomato seedling in solution culture. J. plant Nutr. 17: 173-184.

De Freitas J. R., M. R. Banerjee and J. J. Germida. 1997. Phosphate solubilizing rhizobacteria enhance the growth and yield but not phosphorus uptake of canola (Brassica napus L.). Biol. Fertil. Soils. 24: 358-364.

Dobbelaere, S., J. Vanderleyden and Y.Okon. 2003.Plant growth-promoting effects of diazotrophs in the rhizosphere. CRC Crit Rev Plant Sci.;22:107-149.

Dodd, I.C. and J.M. Ruiz-Lozano 2012. Microbial enhancement of crop resource use efficiency. Curr Opin Biotechnol 23:236242.doi:10.1016/j.copbio.2011.09.005.

Eissa, F.M., M.A. Faith and S.A. El-Shall. 2007. The role of humic acid and rootstock in enhancing salt tolerance of " Le-Conte" pear seedlings.J.Agric. Sci. Mansoura Univ. 32(5): 3651-3666.

El-Komy, H.M.A. 2005. Coimmobilization of Azospirillum lipoferum and Bacillus megatherium for successful phosphorus and nitrogen nutrition of wheat plants. Food Technol. Biotechnol., 43(1):19-27.

El-Wakeil, N. E., and T. N. El-Sebai. 2007. Role of biofertilizer on faba bean growth, yield, and its effect on bean aphid and the associated predators. Res. J. Agric. Biol. Sci, 3(6): 800-807.

Gamalero, E., M. G.Martinotti, A. Trotta, P. Lemanceau, and G. Berta. 2002.Morphogenetic modifications induced by Pseudomonas fluorescens A6RI and Glomus mosseae BEG12 in the root system of tomato differ according to plant growth conditions. New phytologist, 155(2): 293300.

Gerdemann, J.W. and T.H. Nicolson .1963. Spores of mycorrhizal Endogone extracted from soil by wet sieving and decanting. Trans. Brit. Mycol. Soc. 46: 235244.

Ghaith, M. W. 2009. Development of irrigation system on Manzanillo Olive trees under El-Maghara area conditions. Ph.D. thesis. Faculty of Environmental Agricultural Sciences (El-Arish), Suez Canal University.

Glick BR. 1995. The enhancement of plant growth by freeliving bacteria. Can J Microbiol. ;41:109-117.

Giovannetti, M. and B. Mosse. 1980. An evaluation of techniques for measuring vesicular-arbuscular mycorrhizae infection in roots, New Phytologist, 84: 489-500.

Hartwigsen, J. and R. Evansmichael. 2000. Humic acid and substrate treatments promote seedling root development. Hort. Sci. 7:1231-1233. 
Leyval, C., K. Turnau and K. Haselwandter. 1997. Effect of heavy metal pollution on mycorrhizal colonization and function: physiological, ecological and applied aspects. Mycorrhiza 7: 139-153

Magdi, T.A., E.M. Selim and A.M. El-Ghamry. 2011.Integrated effects of Bio and mineral fertilizers and humic substances on Growth, yield and nutrient contents of fertigated Cowpea (Vigna unguiculata L.) grown on sandy soils. Journal of Agron. 10(1): 34-39.

Massoud,.O.N., M.M.I. Afifi, Y.S. El-Akshar and G.A.M. ElSayed.2013. Impact of biofertilizers and humic acid on the growth and yield of Wheat grown in reclaimed sandy soil. Res. J. of Agric. and Bio. Sci., 9(2): 104-113.

Muhammad, Y., A. Kaleem, M. Waqas and Asif T. 2012. Biofertilizers, substitution of synthetic fertilizers in cereals for leveraging agriculture. Crop and Environ. 3(1-2): 62-66.

Munns, R. and M. Tester. 2008. Mechanisms of salinity tolerance. Annu. Rev. Plant Biol. 59: 651-681.

Muscolo, A. and M. Sidari. 2007. Biological activity of humic substances is related to their chemical structure. Soil Sci. Soc. Am.J. 71: 75-85.

Nautiyal, C. S. 1999. An efficient microbiological growth medium for screening phosphate solubilizing microorganisms. FEMS Microbiology Letters. 170: 265270.

Page, A.L. , R.H. Miller and D.R. Keeney.1982.Methods of Soil Analysis. Parts 2. Am. Soc. Agro., Madison, W.1.

Pellerin, S., A. Mollier, C. Morel and C. Plenchette.2007. Effect of incorporation of Brassica napus L. residues in soils on mycorrhizal fungus colonization of roots and phosphorus uptake by maize (Zea mays L.). Europ. J. Agro. 26: 113 -120.

Querejeta, J.I, J.M. Barea, M.F.Allen, F. Caravaca, A. Roldan. 2003. Differential response of $\delta 13 \mathrm{C}$ and water use efficiency to arbuscular mycorrhizal infection in two arid land woody plant species. Oecologia 135:510-515

Rojas-Tapias, D., A. Moreno-Galvan, S. Pardo-Diaz, M. Obando, D. Rivera and R. Bonilla. 2012. Effect of inoculation with plant growth-promoting bacteria (PGPB) on amelioration of saline stress in maize (Zeamays). Appl Soil Ecol 61:264-72. doi:10.1016/j.apsoil.2012.01.006
Scher, F. M., and R. Baker. 1982. Effect of Pseudomonas putida and a synthetic iron chelator on induction of soil suppressiveness to Fusarium wilt pathogens. Phytopathology. 72(12): 1567-1573.

Schmdit, W., S. Santi, R. Pinton and Z. Varanini .2007. Water- extractable humic substances alter root development and epidermal cell pattern in Arabidopsis. Plant \&Soil 300: 259-267

Sepaskhah, A.R and N.Yarami. 2010. Evaluation of macroscopic water extraction model for salinity and water stress in saffron yield production. Inter. J. Plant Production. 4: 175- 186.

Snedecor, G. W., and W. G. Cochran. 1967.statistical methods, ed 6, Ames, Iowa, Iowa State University Press, Section, 12, 349-352.

Varanini, Z. and R. Pinton. 2001. Direct versus indirect effects of soil humic substances on plant growth and nutrition. In: The rhizosphere: biochemistry and organic substances at the soil-plant interface (Pinton R., Varanini Z., Nannipieri P., eds). Marcel Dekker Inc, NY, USA. pp. 141-157

Vessey, J.K. 2003. Plant growth promoting rhizobacteria as biofertilizers. Plant Soil 255: 571-586. doi:10.1023/a:1026037216893

Vivas A, A. Marulanda, J. Ruiz-Lozano, J. Barea and R. Azcón. 2003. Influence of a Bacillus sp. on physiological activities of two arbuscular mycorrhizal fungi and on plant responses to PEGinduced drought stress. Mycorrhiza 13:249-256. doi:10.1007/s00572003-0223-z

Waksman, S.A. and H.A. Lechevalier. 1962. Description of antibiotics. pp.206-307. In The Actinomycetes vol III: Antibiotics of Actinomycetes. The Williams \& Wilkins Company, Baltimore.

Waller, R. A. and D. B. Duncan. 1969.A Bayes rule for the symmetric multiple comparisons problem. J. Am Statistical Association, 64(328):1484-1503.

Zandonadi, D.B., L.P.Canellas and A. Rocha Façanha. 2007. Indoleacetic and humic acids induce lateral root development through a concerted plasmalemma and tonoplast H+pumps activation. Planta, 225: 1583-1595.

Zhu, J.K., 2001. Plant salt tolerance. Trends Plant Sci., 6: 6671. 
الملخص العربي

تأثثير بعض معاملات التسميد الحيوي والهيوميك اسيد على نمو شتلات الزيتون تحت ظروف مستويات مختلفة من الاجهاد الملحي

$$
\text { منى مرسى الثاذلي، وائل موسى غيث الاجبث }
$$

كما ان زيادة تركيز حمض الهيوميك مسن (0, · السى

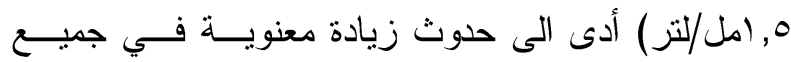

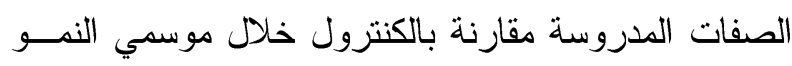

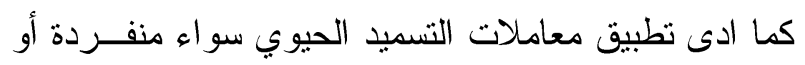

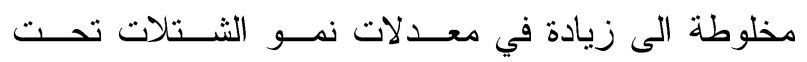
التركيز ات المختلفة للملوحة وأوضحت الدراسة ان استخدام مخلـوط مــن الاســـدة

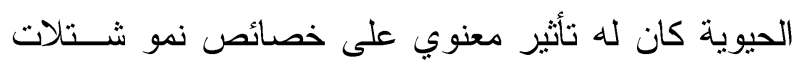
الزيتون ووزن مجموعها الجذري والخضــري ومحتــوى لئه اور اقها من العناصر الغذائية مقارنة بالكنترول و المعاملات وندري الفردية و التي تأثرت تأثر المعنويا ايجابيا بزيادة نركيز الهيوميك

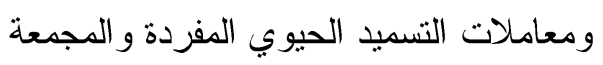
كما ان المعاملة بمخلوط من الاسمدة الحيوية ادت الــى قيم عالية من الخواص الميكروبيولوجية للتربة مثل الاعداد

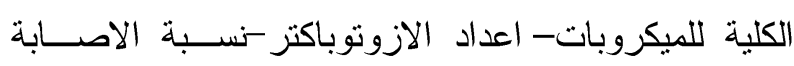

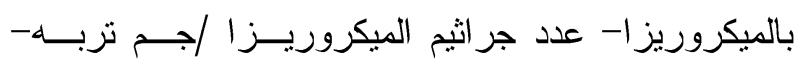

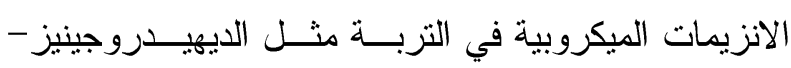
النيتروجينيز و الفوسفاتيز ولذلك فانه لتخفيف الاثر الســلبي للملوحة المرتفعة على شتلات الزيتون نوصــى باســـخدام

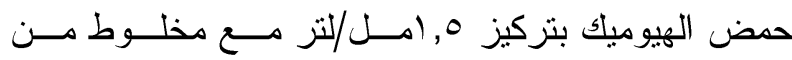

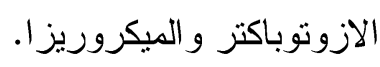

تتو اجد الاملاح طبيعيا فى الترب ومياه الري. الملوحسه

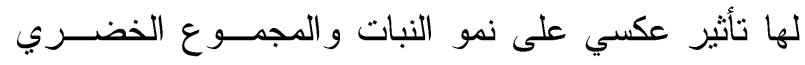

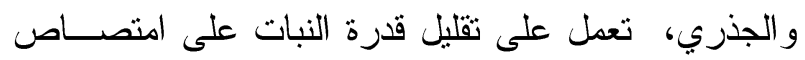

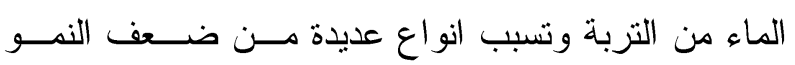
و الانتاجيه

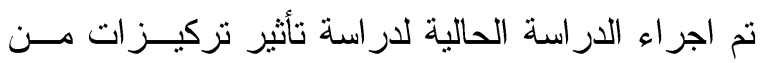

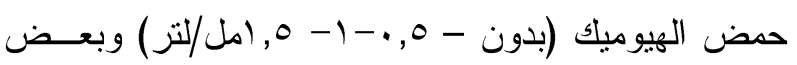
معاملات التسميد الحيوى (كنترول- ازوتوباكتر كروكوكک

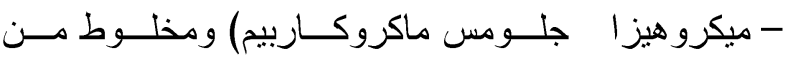

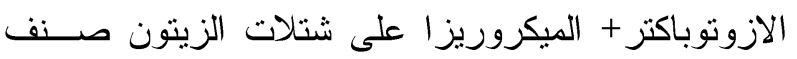

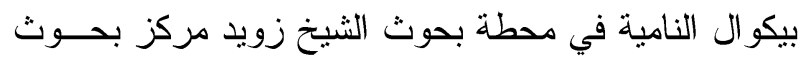
الصحر اء- محافظة شمال سيناء وقد أظهرت النتائج طبقا لقياسات النمو ان معدل الملوحة

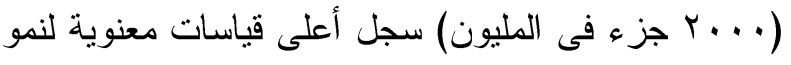

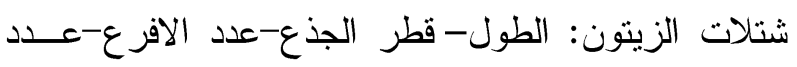

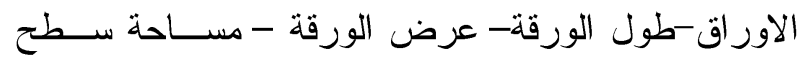
الورقة و ايضـا الوزن الخضرى و الجاف للمجموع الخضرى لورى

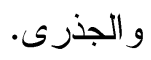
وكانت اقل قياسات تم تسجيلها لمستوى الملوحة (.... جزء فى المليون خلال موسمى النمو) وقد اعطـى معـدل

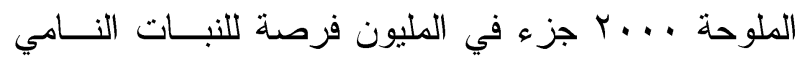

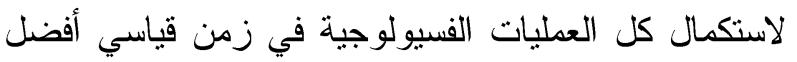
من التركيزات العالية لمياه الري لمئي وقد أدى التركيز العالي للملوحة الى حدوث نقص فيز لتى جميع القياسات المدروسة خلال موسمي النمو. 